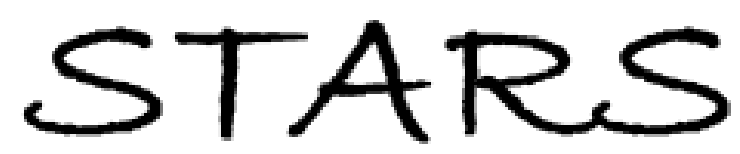

University of Central Florida

STARS

\title{
Work-family Conflict And Performance Evaluations: Who Gets A Break?
}

Kara Hickson

University of Central Florida

Part of the Psychology Commons

Find similar works at: https://stars.library.ucf.edu/etd

University of Central Florida Libraries http://library.ucf.edu

This Doctoral Dissertation (Open Access) is brought to you for free and open access by STARS. It has been accepted for inclusion in Electronic Theses and Dissertations, 2004-2019 by an authorized administrator of STARS. For more information, please contact STARS@ucf.edu.

\section{STARS Citation}

Hickson, Kara, "Work-family Conflict And Performance Evaluations: Who Gets A Break?" (2008). Electronic Theses and Dissertations, 2004-2019. 3769.

https://stars.library.ucf.edu/etd/3769

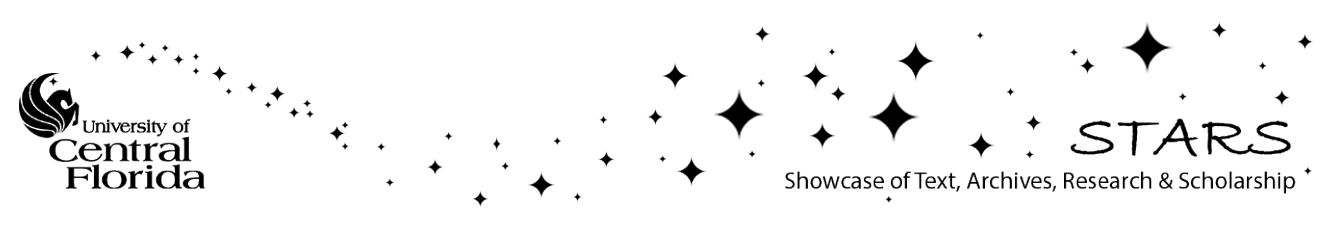


WORK-FAMILY CONFLICT AND PERFORMANCE EVALUATIONS: WHO GETS A BREAK?

by

KARA C. HICKSON

B.S. University of Central Florida, 1994

M.S. University of Central Florida, 2002

A dissertation submitted in partial fulfillment of the requirements

for the degree of Doctor of Philosophy

in the Department of Psychology

in the College of Sciences

at the University of Central Florida

Orlando, Florida

Spring Term

2008

Major Professor: Barbara A. Fritzsche 


\begin{abstract}
Forty percent of employed parents report that they experience work-family conflict (Galinsky, Bond, \& Friedman, 1993). Work-family conflict (WFC) exists when role pressures from the work and family domains are mutually incompatible. WFC is associated with decreases in family, job, and life satisfaction and physical health; intention to quit one's job; and increases in workplace absenteeism. Women may be more impacted by WFC than men, as women report completing $65-80 \%$ of the child care (Sayer, 2001) and spend 80 hours per week fulfilling work and home responsibilities (Cowan, 1983). Research suggests that WFC can be reduced with social support, such as co-workers providing assistance when family interferes with work (Carlson \& Perrewé, 1999). It is unclear whether parents 'get a break' or are penalized by coworkers. The purpose of the present study was to examine co-workers' reactions to individuals who experience WFC. Based on sex role theory and attribution theory, it was predicted that women, people who experience family interference with work, and those who have more control over the work interference would be helped less and evaluated more poorly on a team task than men, people who experience non-family related work interference, and those who have less control over the work interference. A laboratory experiment was conducted in which participants signed up for a team-based study. The teammate was a confederate who was late for the study. Teammate control over the tardiness (unexpected physician's visit versus forgotten physician's appointment), type of work conflict (self- versus family-related), and gender of the teammate were manipulated. After learning about the reasons for the tardiness of their teammate, the 218 participants (63\% female; 59\% Caucasian) decided whether to help the late teammate by completing a word sort task for them or letting the late teammate make up the work after the experiment. When the teammate arrived, the participants completed a team task and then evaluated the task performance of their teammate. None of the hypotheses were confirmed in this
\end{abstract}


study. However, exploratory analyses showed that people who had more control over the tardiness were rated lower than people who had less control over the tardiness. Contrary to expectations, exploratory analyses also showed that men rated women who were late to the study for a family-related reason higher than women who were late due to a self-related reason. These findings suggest that male co-workers may give women a break when they experience family interference with work. Implications for future research and practice are discussed. 
I dedicate this dissertation to my Mom...a woman who balances career and family responsibilities and inspires me to live with integrity and achieve greatness in all of my endeavors. She continues to provide me with the social support that I need to achieve my educational, family, and career-related goals. 


\section{ACKNOWLEDGMENTS}

I extend utmost appreciation to my advisor, Dr. Barbara Fritzsche. She has acted as a mentor, has supported me through academic, career, and personal struggles, and has spent countless hours reviewing draft after draft of this work, always offering suggestions for improvement.

I appreciate the contributions of the other committee and faculty members who were involved in this project: Dr. Robert Dipboye, Dr. Stacey Dunn, Dr. Karen Mottarella, and Dr. Beth Young. Your input contributed to the quality of this project. Many thanks to my research assistants, to whom I am forever indebted for their assistance with this project: David Arenas, Myralda Jones, Sarah Keyes, William Lively, Jackie Malone, Eddie Oakes, MaryFrances Papadakis, Gabriel Santos, Jamie Seiger, Ana Timmer, Victoria Thompson, Maggie Walter, and Christopher Weise. Without them, it would have been impossible to complete an experiment that required one hour and two experimenters per session. Hopefully they don't shudder at the mere mention of a 20 Questions game.

Thank you to all of my family and friends who supported me throughout the graduate school journey. You have provided much-needed encouragement and support over the years. Thank you Grandaddy - your legacy in education and the community inspires me. Thank you PopPop for building an environment where family members know they can count on each other. Thank you Gram and Memom, for demonstrating that working women can raise beautiful families. Thank you Mom and Dad; you have made it happen through all of my 31 years (and then some). You worked hard to establish a successful business, yet Josh and I never felt neglected of time or love. Thank you Joshua...I could not build a better brother than you. You are always there to lend a helping hand or just make me laugh. And thank you Adam, for making 
me smile like I have never smiled before. May we be as successful as our own parents, in figuring out how to make work and family work well. 


\section{TABLE OF CONTENTS}

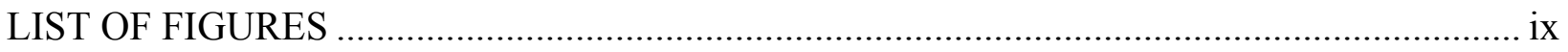

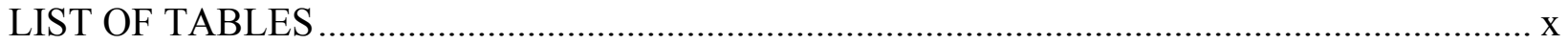

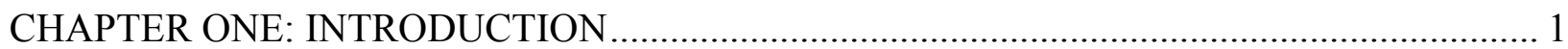

CHAPTER TWO: LITERATURE REVIEW …................................................................ 5

Work-Family Conflict Theory and Research.......................................................... 5

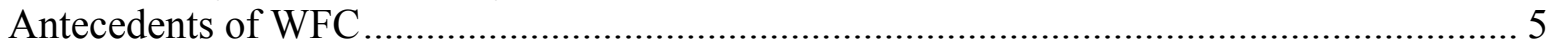

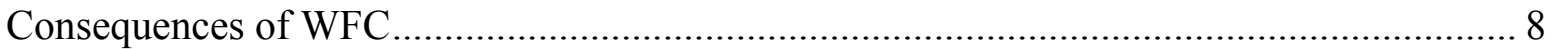

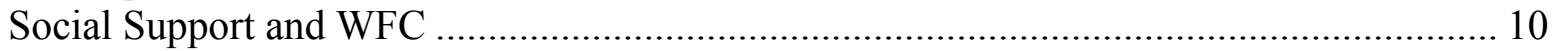

Differences in Workplace Experiences for Women and Men with Families ..................... 12

Gender Roles and Workplace Experiences........................................................... 15

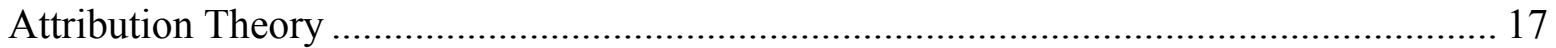

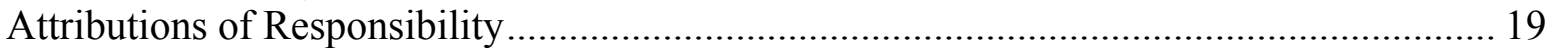

The Emotional Repercussions of Judgments of Responsibility (Weiner, 1995, p. 16) ........ 20

How Does Attribution Theory Explain Differences in Reactions? ................................. 22

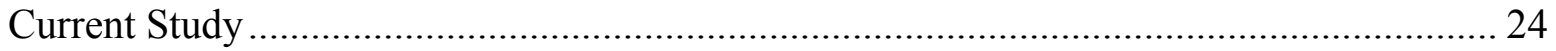

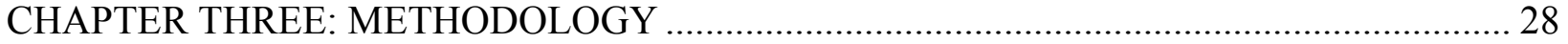

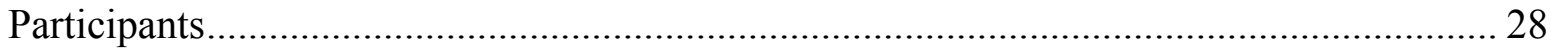

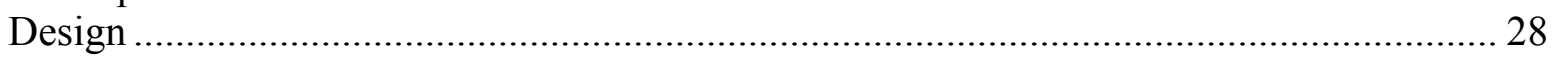

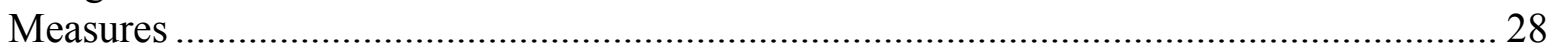

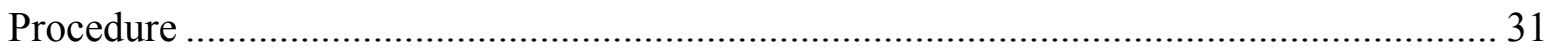

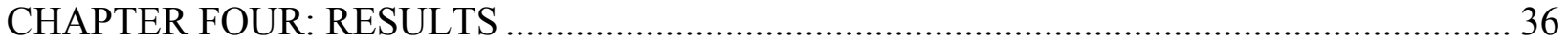

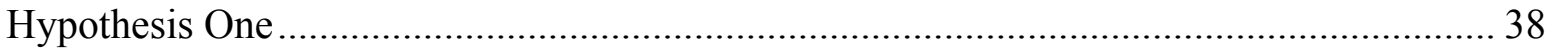

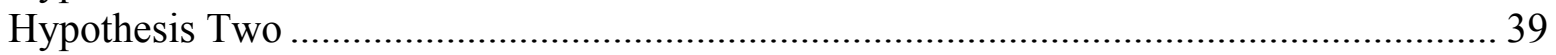

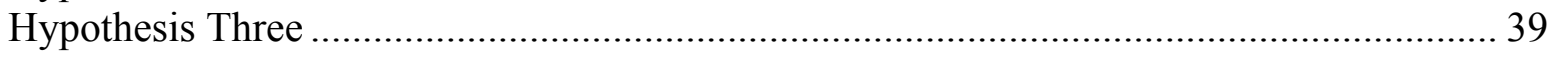

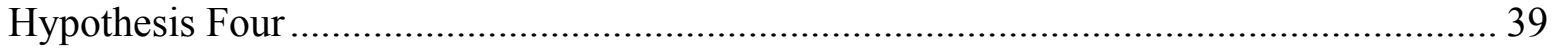

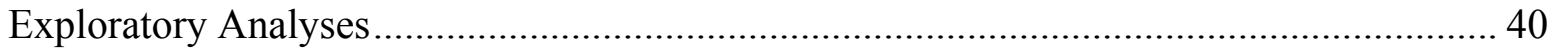

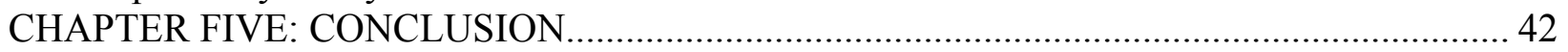

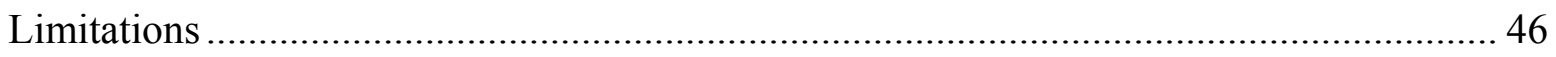

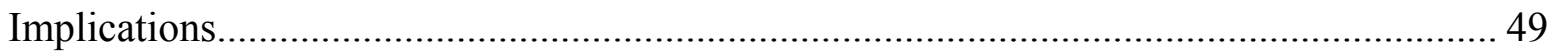

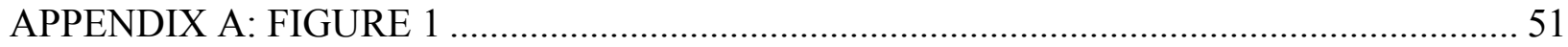

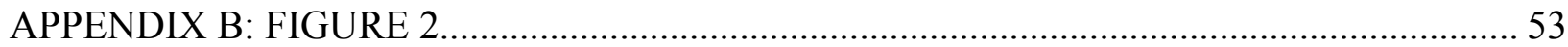

APPENDIX C: INFORMED CONSENT LETTER (PART ONE)........................................ 55

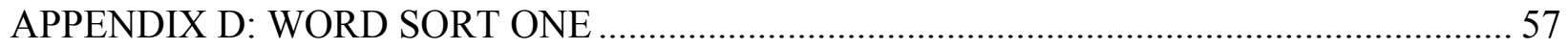

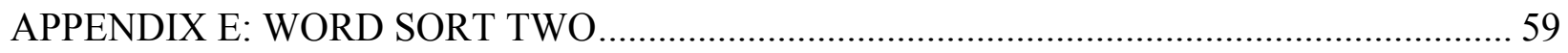

APPENDIX F: PERFORMANCE EVALUATION RATING ......................................... 61

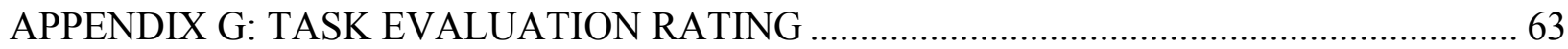

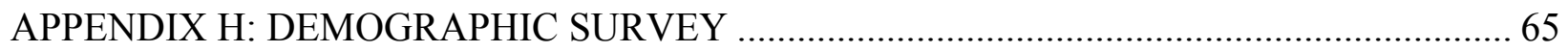

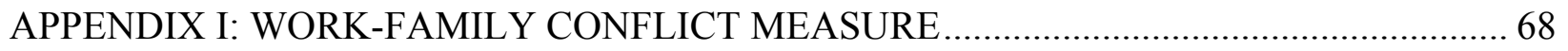

APPENDIX J: ATTITUDES TOWARD TEAMWORK SURVEY …................................ 71

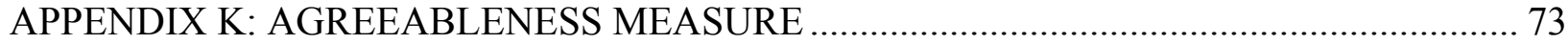

APPENDIX L: PROSOCIAL PERSONALITY BATTERY …........................................... 75

APPENDIX M: BEM SEX ROLE INVENTORY ............................................................ 78

APPENDIX N: INFORMED CONSENT LETTER (PART TWO) ...................................... 80

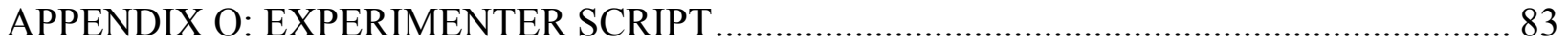

APPENDIX P: PARTICIPANT 20 QUESTIONS ........................................................... 86 


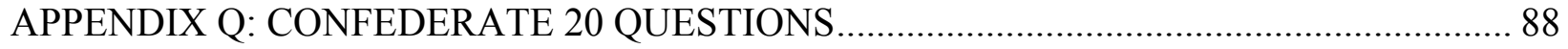

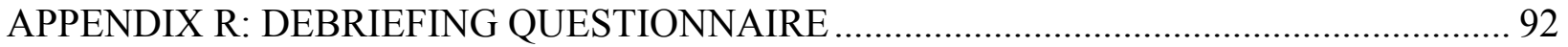

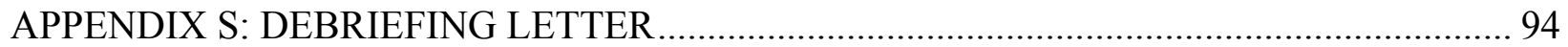

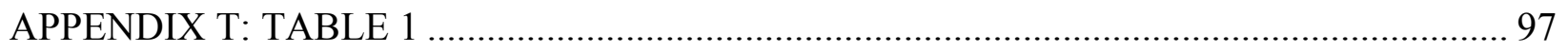

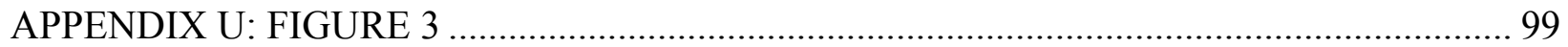

APPENDIX V: IRB HUMAN SUBJECTS PERMISSION LETTER ................................. 101

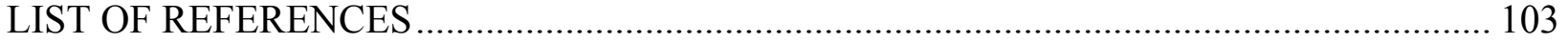




\section{LIST OF FIGURES}

Figure 1 Work-family conflict model ......................................................................... 52

Figure 2 Work-family conflict model with social support as an antecedent to stressors ............ 54 Figure 3 Interaction between participant gender, teammate gender, and type of conflict (familyrelated versus self-related). ..... 100 


\section{LIST OF TABLES}

\section{Table 1}

Descriptive Statistics, Internal Consistency Estimates, and Intercorrelations for Individual Differences Measures and Evaluation and Task Ratings... 


\section{CHAPTER ONE: INTRODUCTION}

"I've learned that you can't have everything and do everything at the same time"

(Winfrey, 2003). The words of one of the world's most successful women likely resonate with all of us who desire to achieve success and effectively manage life's competing roles. Work is one competing role that is both important and demanding. One study found that $78 \%$ of U.S. employees reported that work was among the three most important things in their lives (England \& Misumi, 1986). Only $7.2 \%$ of the U.S. sample stated that work was the least important thing in their lives. In a survey assessing the meaning of work for senior managers, middle managers, supervisors, and professional employees, U.S. employees indicated the absolute importance of working as 5.58 on a 7-point scale (Lundberg \& Peterson, 1994). Not only is work an important life role, it requires a large amount of time. In a managerial stress survey, 1,152 participants from English-speaking Anglo countries (Australia, Canada, England, New Zealand, and U.S.) reported working an average of 49.3 hours per week $(S D=8.2$ hours; range $=30-80$ hours $)$. Almost 30\% of the labor force works 49 or more hours per week (U.S. Department of Labor, Bureau of Labor Statistics, 2000). In addition, working 50+ hours per week is often necessary for employees in management and professional positions who desire promotion (Bailyn, 1993; Kanter, 1977).

For many people, family is also an important and demanding life role. In Lundberg and Peterson's (1994) study, family was ranked as the single most important life role for U.S. employees. In addition to being important, family responsibilities are very demanding. Women seem to be more affected by family care responsibilities than are men, as women report doing $65-80 \%$ of the child care (Sayer, 2001) and more than $70 \%$ of high burden elder care (National Alliance for Caregiving and American Association of Retired Persons, 2004). For example, women complete an average of 3.5 hours of childcare per workday and men perform an average of 2.7 hours of childcare per workday (Bond, Thompson, Galinsky, \& Prottas, 2002). Other 
research shows similar trends, as fathers and mothers, respectively, report working an average of 50 and 80 hours per week in employment (outside of the home) and household work (Cowan, 1983). These demands are even greater for employees with young children. For example, employed mothers of children under age three reported working 90 hours per week on child care and outside employment duties (Rexroat \& Shehan, 1987).

With such great demands at work and at home, it can be difficult to balance family and work responsibilities or to "have everything and do everything at the same time" (Winfrey, 2003). One way to balance the demands of work and family roles is to assume the "one partner as full-time breadwinner, one partner as full-time homemaker" family type. In this family type, one partner assumes the majority of the family responsibilities and the other partner assumes the financial responsibilities. However, fewer than $3 \%$ of U.S. families fit the father as breadwinner and stay-at-home mother mold (Gilbert \& Rader, 2001). Instead, most modern families take different forms. Many families include two parents who are employed outside of the home. In fact, in $2003,60.7 \%$ of married couples with children younger than 18 years old were dualearner families (U.S. Census Bureau, 2005). In other families, one parent handles the family and work responsibilities without the help of a partner. For example, in 1999, in $20.1 \%$ of families with children younger than 6 years old and $22 \%$ of families with children between 6 and 17 years old, the child (children) was (were) living with one parent who was in the labor force (U.S. Census Bureau, 2000). When both parents are, or the sole household parent is, employed, this creates challenges in balancing the demands of work and home life. In fact, $40 \%$ of employed parents report that they experience work-family conflict at least some of the time (Galinsky, Bond, \& Friedman, 1993). Work-family conflict (WFC) is a type of interrole conflict in which 
role pressures from the work and family domains are mutually incompatible to some degree (Kahn, Wolfe, Quinn, Snoek, \& Rosenthal, 1964; Greenhaus \& Beutell, 1985)

If not remedied, WFC can lead to problems in both the work and home environments. For instance, individuals with higher levels of WFC have experienced lower family satisfaction (Beutell \& Wittig-Berman, 1999; Carlson \& Kacmar, 2000; Carlson \& Perrewé, 1999), lower job satisfaction (Boles \& Babin, 1996; Boles, Johnston, \& Hair, 1997; Carlson \& Perrewé, 1999; Good, Sisler, \& Gentry, 1988; Kossek \& Ozeki, 1998), lower life satisfaction (Beutell \& WittigBerman, 1999), lower quality of family life (Higgins, Duxbury, \& Irving, 1992), and poorer physical health (Frone, Russell, \& Cooper, 1997) than those with lower levels of WFC. WFC has also been associated with negative workplace outcomes, such as intention to quit (Burke, 1994; Good, Page, \& Young, 1996; Good et al., 1988) and increases in workplace absenteeism (Goff, Mount, \& Jamison, 1990). Social support has been related to lower WFC (Carlson \& Perrewé, 1999; Goff et al., 1990; Nielson, Carlson, \& Lankau, 2001). Thus, social support is a tool that individuals can seek in their quest to have and do everything. However, no studies were found that directly examine differences in the amount of social support that colleagues provide to employees who juggle work and family roles.

To demonstrate the need for research examining difference in received social support, I will first review the WFC literature, including its antecedents and outcomes. Next, I will discuss how social support reduces WFC and its negative outcomes. Then, I will describe the influences of gender role expectations and family responsibilities on employees' workplace experiences and outcomes. Specifically, I will discuss research that shows that parents are perceived as less agentic and committed to the job than nonparents (Fuegen, Biernat, Haines, \& Deaux, 2004), that parenthood negatively impacts employed women, but not employed men (Cuddy, Fiske, \& 
Glick, 2004; Fuegen et al., 2004), that employed women are viewed more negatively than employed men when they behave assertively (Costrich, Feinstein, Kiddler, Marecek, \& Pascale, 1975; Eagly, Makhijani, \& Klonsky, 1992), and that employed mothers are viewed as "bad mothers" if they choose to work (Gorman \& Fritzsche, 2002). I will demonstrate how attribution theory and expectations about employed parents suggest that employees (especially female employees) who report family interference with work are likely to receive lower performance evaluation ratings and less social support than employees who do not report family interference with work. Then, I will report the findings of my laboratory-based experiment that investigated workplace outcomes (performance evaluations and social support) for individuals who would benefit by receiving help. In this experiment, I assessed the impact of an individual's gender, control over the reason for needing help, and whether the need for help was self-related or childrelated on performance evaluations and the degree to which these individuals received social support from teammates. After reviewing the findings, I will discuss the implications and potential applications of these results. 


\section{CHAPTER TWO: LITERATURE REVIEW}

\section{Work-Family Conflict Theory and Research}

A basic model of the work-family conflict (WFC) process is provided in Appendix A (Carlson \& Kacmar, 2000). WFC can occur via two major routes. WFC can occur via work interference with family (WIF) and/or family interference with work (FIW, sometimes called family-work conflict [FWC]). WIF is the extent to which work matters interfere with home matters. For example, WIF occurs when employees must work until late in the evening, which

prevents them from spending time with family. FIW is the degree to which family matters invade work matters. An example of FIW is when employees must leave work early to pick up their children from day care. FIW and WIF are positively related (Carlson \& Kacmar, 2000; Thompson \& Blau, 1993). Thus, the more employees' home lives interfere with their work lives, the more their work lives interfere with their home lives. If family responsibilities are negatively impacting employees' workplace performance, then it is more likely that their work responsibilities will lead them to be less effective family members. Antecedents of WFC

In the work realm, several factors are associated with work-family conflict. Work-role ambiguity, work-role conflict, work time demands, and job involvement are often specified as antecedents to WFC. Work-role ambiguity exists when employees are not certain about the essential requirements of their job. For example, salespersons may experience work-role ambiguity when they are uncertain about the relative importance of customer satisfaction and increased sales — two important, but perhaps competing, demands. In general, work-role 
ambiguity is positively related to $\mathrm{WFC}^{1}$ (Boles \& Babin, 1996; Boles et al., 1997; Good et al., 1988).

Work-role conflict exists when employees are faced with incompatible demands presented by different people or workgroups. An example of work-role conflict is a situation in which employees receive and must complete two different work projects for two different work teams, on the same day. Increases in work-role conflict are associated with increases in WFC (Boles \& Babin, 1996; Boles et al., 1997; Good et al., 1988; and Higgins et al., 1992). It has been suggested that role stress such as employee work-role ambiguity and work-role conflict lead to perceptions of a stressful work environment, which in turn is associated with WFC (Greenhaus \& Beutell, 1985; Williams \& Alliger, 1994).

When employees have greater work time demands, they experience more WFC (Carlson \& Perrewé, 1999) and WIF (Carlson \& Kacmar, 2000). In general, elevated job involvement is associated with increased WFC (Beutell \& Wittig-Berman, 1999; Carlson \& Perrewé, 1999; Higgins et al., 1992; Thompson \& Blau, 1993) and WIF (Carlson \& Kacmar, 2000). However, Thompson and Blau (1993) found that job involvement was negatively related to family-work conflict (FWC). Perhaps employees with lower levels of FWC have more resources (e.g., time, energy) to contribute to work, which may lead to increased job involvement.

In addition to work-related factors, several home-related factors are linked to workfamily conflict. Family-role ambiguity is positively related to WFC (Carlson \& Perrewé, 1999) and FIW (Carlson \& Kacmar, 2000). An example of family-role ambiguity is when parents do not know if it is more important to be disciplinarians or financial providers for the family. Family-role conflict is also positively related to WFC (Carlson \& Perrewé, 1999; Higgins et al.,

\footnotetext{
${ }^{1}$ Some studies distinguish between WIF and FIW forms of WFC, others discuss WFC in its general form. When such distinctions are made, the results are presented accordingly.
} 
1992) and FIW (Carlson \& Kacmar, 2000). If parents have to take one child to band practice at the same time another child has a dentist appointment, parents may experience family-role conflict. Family time demands are also positively related to WFC (Carlson \& Perrewé, 1999) and to FIW (Carlson \& Kacmar, 2000). The more time family requires, the more WFC experienced.

Family involvement is the extent to which family and involvement with one's family is central to an individual's life. Research has shown that family involvement is related to WFC (Carlson \& Perrewé, 1999) and FIW (Carlson \& Kacmar, 2000). Thus, an increased involvement in one's family life yields an increased likelihood of experiencing WFC.

Several other family-related factors not included in this model are associated with WFC. For example, increased marital role commitment has been associated with lower levels of WFC (Livingston, Burley, \& Springer, 1996). Thus, a solid home foundation, in which both partners are supportive of the others' problems, may help to alleviate WFC. Findings on the relationship between number of children and WFC have been mixed. Studies have indicated positive (Boles et al., 1997), negative (Beutell \& Wittig-Berman, 1999), and no relationships (Goff et al., 1990) between number of children and work-family conflict. Having more children may alleviate parental burden, as older children can help with household and child care duties. This reduction in household demands can lead to a decrease in the amount of experienced WFC. However, if the children are not old enough to help or if parents do not require that the children help, this could generate increased WFC. Parents with more children have greater household duties (e.g., laundry, cleaning), more child activities to attend (e.g., sports, dance, school activities), and more general parental support to provide (e.g., emotional support). Thus, there is potential for different relationships between number of children and WFC, depending on one's family situation. 


\section{Consequences of WFC}

If not remedied, WFC can lead to several negative personal and professional outcomes. Increased WFC is associated with decreased satisfaction in several life realms. For example, individuals with higher WFC (Beutell \& Wittig-Berman, 1999; Carlson \& Kacmar, 2000; Carlson \& Perrewé, 1999) experience lower levels of family satisfaction, which is in turn related to decreases in life satisfaction (Beutell \& Wittig-Berman, 1999). Research has shown that WFC and FWC (Kossek \& Ozeki, 1998) are negatively related to life satisfaction. Increases in WFC are also associated with decreases in work-related satisfaction. Higher WFC is associated with decreased job satisfaction in general (Boles \& Babin, 1996; Boles et al., 1997; Carlson \& Perrewé, 1999; Good et al., 1988; Kossek \& Ozeki, 1998) as well as decreased job satisfaction for entry-level managers (Good et al., 1996). FWC is negatively related to job satisfaction (Kossek \& Ozeki, 1998; Thompson \& Blau, 1993). For a sample of police officers, WFC was negatively related to job satisfaction (Burke, 1994). This relationship existed for the health and safety (spouse's concerns about partner's safety on job) and exemplary behavior (family has to be on best behavior due to spouse's job) components of WFC, as specified in the study. Increases in FWC have also been associated with decreases in career satisfaction. Career satisfaction is measured by items related to career progress and success, such as income and new skill development (Beutell \& Wittig-Berman, 1999). It is possible that family responsibilities detract from an individual's time and energy resources, which may slow career progress. Thus, many studies have shown that WFC has been associated with decreased satisfaction in many important life areas; people who experience WFC tend to be less satisfied.

Employees who experience WFC also exhibit negative life-quality-related and healthrelated outcomes. For example, Higgins and colleagues (1992) found that increased levels of 
WFC are associated with lower quality of work and family life. Burke (1994) found that the type of WFC that impedes an individual's self-improvement efforts was associated with negative feeling states. Williams and Alliger (1994) showed that the juggling of work and family tasks had a negative impact on feelings of distress and calmness. In addition, high WFC is associated with emotional exhaustion (Boles et al., 1997). Work-family conflict is also associated with longitudinal health-related outcomes. In a survey of 267 employed parents that was conducted in 1989 and again in 1993, Frone, Russell, and Cooper (1997) found that greater family-to-work conflict was associated with higher levels of depression, poor physical health, and hypertension. They also found that work-to-family conflict was related to heavy alcohol consumption.

In addition to the negative personal outcomes associated with WFC, WFC is related to outcomes that are maladaptive for employers. For instance, higher scores on the health and safety (concerns of police officer's spouse regarding the officer's job safety) component of WFC were associated with higher intentions to quit in a sample of police officers (Burke, 1994). Higher work-family conflict was also associated with greater intentions to leave the organization in a sample of entry-level executives (Good et al., 1996). In addition, research has shown that higher WFC is related increases in absenteeism at work (Goff et al., 1990).

Thus, research has shown that WFC is associated with several negative outcomes, many of which are detrimental to organizations. Therefore, it is in organizations' best interests to understand WFC and the means by which it can be reduced. WFC's negative effects on work performance may simply result from an inability to adequately balance the demands of multiple roles. Other explanations of this relationship will be explored in the following sections. Regardless of the reason for its impact on work performance, it may be possible to alleviate WFC with the use of coping strategies, such as social support. 


\section{Social Support and WFC}

Social support has been shown to help individuals who experience WFC. Social support is defined as an interpersonal transaction that involves emotional concern, instrumental aid, information, or appraisal (House, 1981). Procuring support, as a coping strategy, is negatively related to anticipated WFC (Burley, 1994). Social support can be obtained in the work environment or in the family realm. Both types of social support are negatively related to WFC (Carlson \& Perrewé, 1999). Work social support can be provided by anyone in the workplacecoworkers, supervisors, or subordinates. A coworker could provide work social support by assisting another coworker with completion of a project, because the latter coworker has to leave work early on a particular day. A manager could provide work social support by allowing employees to change their work hours for the week to accommodate family emergencies. Goff, Mount, and Jamison (1990) found that as support from one's supervisor increases, work-family conflict decreases. Nielson, Carlson, and Lankau (2001) also examined the impact of mentor support on WFC. Employees with mentors report less general WFC, especially family-work conflict, than employees without mentors. In addition, mentor supportiveness of an employee's desire to balance work and family roles was the strongest predictor of reduced WFC.

The social support models have differed with regard to placement of social support in the WFC process. Carlson and Perrewe (1999) provided a summary of this literature in their paper that examined the relationship between social support and WFC. The summary of their findings is provided here. Some research specifies social support as a moderating variable between the stressors/antecedents of WFC (i.e., role conflict, time demands and ambiguity) and experienced WFC. Thus, increases in social support would help to decrease the strength of the relationship between the antecedents of WFC and experienced WFC; even if a person encountered the 
antecedents of WFC, social support would decrease the likelihood that he or she would actually experience WFC. Evidence for social support as a moderator in the stressors-WFC relationship is limited, with some studies showing no support of the relationship and some showing mixed support (i.e., only some of the proposed interactions were statistically significant). Other research specifies social support as an intervening (mediator) variable between the antecedents of WFC and experienced WFC. In this situation, the experience of stressors would trigger the need for social support, and acquisition of social support would serve to reduce experienced WFC. Prior research has shown support for social support as a mediating variable between the antecedents of WFC and experienced WFC. Finally, social support can be conceptualized as an antecedent to the WFC process. In this case, social support would decrease the impacts of role conflict, time demands, and ambiguity, which would then decrease experienced WFC. Existing research has also shown support for social support as an antecedent to the experience of stressors in the WFC process (Carlson \& Perrewe, 1999).

To help determine the best placement of social support in a model describing the WFC process, Carlson and Perrewe (1999) examined WFC data from a sample of 403 state government workers in the southeast. They found that social support was best specified as an antecedent to perceived stressors (see Appendix B). Thus, work social support helped to decrease work role conflict, work time demands, and work role ambiguity. In turn, work role conflict was negatively related to job satisfaction. In addition, work social support had a direct relationship with job satisfaction; as work social support increased, people were more satisfied with their jobs. Thus, social support is quite beneficial to employees who experience WFC-related problems. 


\section{Differences in Workplace Experiences for Women and Men with Families}

Although research has examined the impact of social support in the WFC process, no studies were found that examined differences in social support experiences between employees with and without family responsibilities. However, research has shown that employees with and without children are perceived differently in the workplace (Fuegen et al., 2004). Further, studies have suggested that gender interacts with parental status, such that employed female parents suffer in terms of perceptions of competence and employment decisions (Cuddy, Fiske, \& Glick, 2004; Fuegen et al., 2004).

In a study assessing the influence of gender and parental status on employment decisions (Fuegen et al., 2004), participants in the experimental conditions evaluated one of four job applicants who differed by gender (male or female) and marital/family status (single or married with two children). Parents were viewed as less committed to their work, less available to the job, and less agentic than non-parents (Fuegen et al., 2004). Participants were also asked to specify the performance standards and time commitment standards they would expect from the job applicants. Gender of the parent impacted the results, such that female parents had a disadvantage. Specifically, participants had lower performance expectations for male parents than female parents and male non-parents. For example, male parents could have lower scores than female parents and male non-parents on a standardized ability test, worse letters of recommendation, lower scores on skills tests and still be hired. In addition, male parents were expected to be available to work fewer hours per week and could take more sick days than male non-parents. Thus, with regard to performance and time-commitment standards, male parents fared better than female parents and male and female non-parents. 
Regarding opportunity for hiring and promotion, men were equally likely to be promoted, whether they were parents or non-parents. However, women were less likely to be promoted when they were parents than non-parents. Thus, parental status was more beneficial to men than women. "In sum, parents were judged to be poorly suited to the workplace compared to nonparents, and mothers were disadvantaged relative to fathers" (p. 748). The authors suggest that the main effects of parental status support social role theory, which proposes that the parental role, not gender, influences judgments about mothers and fathers. Further, the interactions between gender and parental status support a shifting standards model, which occurs when stereotypes prompt the setting of different standards for groups. The standards for mothers and fathers may differ because it is assumed that fathers need the jobs more than mothers and it is expected that women will be less committed to the workplace because they are more concerned with their families than with work.

People also have different perceptions of the warmth and competence of male and female employees depending on their parental status. In turn, these perceptions influence employment decisions. This can lead to women being placed on the mommy track, which results from stereotypes that suggest that women can’t be serious professionals (Schwartz, 1989). Cuddy, Fiske, and Glick’s (2004) “stereotype content model (SCM) distinguishes among qualitatively different types of prejudice based on the relative status and perceived interdependence of target groups" (p. 702). The model shows that people can be perceived as one of four combinations of warmth (high or low) and competence (high or low). Those who are perceived to be low on both dimensions are typically discriminated against and are subject to social exclusion and active harm. Those who are perceived as warm and competent are the in-group and typically receive assistance from and cooperation with other groups. Some people are perceived as high on 
warmth and low on competence, such as the elderly, mentally disabled, physically disabled, and housewives (Cuddy, Norton, \& Fiske, 2005; Fiske, Cuddy, Glick, \& Xu, 2002; Fiske, Xu, Cuddy, \& Glick, 1999), and members of these groups typically elicit pity, a paternalistic response (as they are harmless but pathetic), or occasional admiration. Thus, members of these groups receive assistance, but also may be subject to passive harm. Individuals who are high on competence and low on warmth, such as wealthy people, and Asian, Jewish, and female professionals, typically elicit envy. These stereotypes "predict patterns of discriminatory behavioral intentions including active harm (e.g., attack, sabotage), passive harm (e.g., social exclusion, derogation), helping (e.g., helping, assistance), and cooperation (e.g., association, cooperation)" (Cuddy et al., 2004, p. 705). Therefore, groups high on competence and low on warmth receive resentful cooperation and sometimes, active harm. Women generally fall into one of the mixed categories as they "are typically respected or liked but not both" (Cuddy et al., 2004, p. 705).

In Cuddy, Fiske, and Glick's (2004) study, participants reviewed information about one of four fictitious consultants, in which gender (male or female) and parental status (child or no child) were manipulated. Participants rated the consultants on warmth and competence and indicated how likely they would be to request the consultant, recommend him or her for promotion, and recommend that the corporation invest in him or her for further education and training. Parents, regardless of gender, were rated as warmer than non-parents. However, gender interacted with parental status to impact competence ratings, to the benefit of male parents. Specifically, the working mom was perceived as less competent than the childless female employee. However, the working father and childless working man were not rated differently. 
Thus, parental status had a negative influence on women's competency ratings, but no impact on men's competency ratings.

These contrasting perceptions resulted in different employment decisions for women, depending on their parental status. The childless working woman was more likely to be requested as a consultant, recommended for promotion, and recommended for training than the working mom. Thus, women's parental status had a negative impact on employment decisions.

Therefore, even though the literature pertaining to differences in received social support is limited, research has shown that employees are perceived and treated differently, depending on their parental status. In addition, women seem to be more disadvantaged than men when they choose parenthood and employment. Not only does gender affect treatment in the workplace, there are differences in compensation. For example, working mothers earn $60 \%$ of what working fathers earn (Crosby, Williams, \& Biernat, 2004). These differences in treatment are best explained by gender roles, which affect our judgments about appropriate behaviors for men and women in society and in the workplace.

\section{Gender Roles and Workplace Experiences}

"Gender roles are those shared expectations that apply to individuals on the basis of their socially identified sex" (Eagly, 2000, p. 448). Gender roles are a type of social role. People in the same role (e.g., women) experience similar situational constraints, which yield behaviors that are characteristic of the shared role (e.g., expected nurturing behavior) (Eagly, 2000). Individuals are expected to adhere to their given social roles; those who deviate from expectations are likely to experience negative sanctions (Eagly, 2000). Thus, individuals who "act inappropriately" are punished for their behavior. 
Stereotypes are further perpetuated by descriptive and injunctive norms. Cialdini and Trost (1998) described descriptive norms as "expectations derived from observations of what people do" and injunctive norms as "expectations about what people should do" (Eagly, 2000, p.449). In general, ideal behavior (prescribed by injunctive norms) is guided by typical behavior (descriptive norms). Thus, ideal female behavior is based on what is typical of other females, and gender stereotypes become gender roles (Eagly, 2000). All members of society, regardless of gender, age, social class, and income, hold these expectations about gender roles (Broverman, Vogel, Broverman, Clarkson, \& Rosenkrantz, 1972). Women typically engage in behaviors that are described as communal and men generally act in ways that are described as agentic (Bakan, 1966). Communal behaviors are described as "friendly, unselfish, concerned with others, and emotionally expressive" (Eagly, 2000, p. 449). Agentic behaviors are "independent, masterful, assertive, and instrumentally competent" (Eagly, 2000, p. 449).

Gender roles also interact with specific roles, such as occupational roles. In general, "mainly women occupy the domestic role, somewhat more men than women occupy the employee role, and women are more likely than men to be employed part-time or part-year" (Shelton, 1992). The workplace expectations for women who do choose to work are quite different than those of their male counterparts and failure to adhere to these expectations may be “overt (e.g., losing a job) or subtle (e.g., being ignored, disapproving looks)" (Eagly, 2000, p. 450). For example, research has shown that women who behave assertively and men who behave passively were rated less favorably than women who behave passively and men who behave assertively (Costrich, Feinstein, Kiddler, Marecek, \& Pascale, 1975). A meta-analysis by Eagly, Makhijani, and Klonsky (1992) showed that men with an assertive and directive leadership style were rated higher than women with such a style. However, there were no differences in 
evaluation ratings between men and women with democratic and participative leadership styles. Further, when compared with men in small group interactions, women were likely to be ignored and elicit negative reactions when making competent, task-relevant contributions (Carli, 1995). In addition, women who engage in a dominant style by expressing clear disagreement with another person, speaking directly, rather than tentatively, and behaving extremely competently tend to lose likeability and influence over others (Carli, 1995). Thus, conformity is rewarded with liking and cooperation and nonconformity is punished with rejection and neglect (Eagly, 2000, p. 450). Given these outcomes, nonconformists certainly assess this relationship to ensure that the benefits are worth the costs (Eagly, 2000).

Women are also expected to desire to adhere to these roles. For example, Gorman and Fritzsche (2002) studied perceptions of mothers who choose to return to work or stay home from work after having a child. Thus, to be perceived as communal, mothers either had to be satisfied with their decision to stay at home (permanently or temporarily) or dissatisfied with their decision to return to work. Participants did not view a happily employed mother as a good mother. In addition, new mothers were perceived as most committed to motherhood when they were satisfied with the decision to stay home or dissatisfied with the decision to return to work. Thus, good mothers were conceptualized as those who stayed home (and liked it) or wished they could stay home.

\section{Attribution Theory}

As described, individuals sometimes make attributions and decisions about employees based on factors that are not work-related. For example, working moms were perceived as less competent than childless female employees, but men's parental status did not influence ratings of their competence (Cuddy et al., 2004). In another study (Fuegen et al., 2004), male parents were 
held to lower employment standards than female parents. Further, men were equally likely to be promoted, whether they were parents or non-parents whereas women were less likely to be promoted when they were parents than non-parents. Another study (Cuddy et al., 2004) showed that a childless woman was more likely to be requested as a consultant, recommended for promotion, and recommended for training than a working mom. Additional research showed that mothers should desire to cease employment (temporarily or permanently) after the birth of a child (Gorman \& Fritzsche, 2002). Given the influence of gender and parental status on the attributions and decisions made about employees, attribution theory may be useful in understanding how coworkers' perceptions about other coworkers' WFC explain differences in employee outcomes.

Jones and Nisbett (1987) suggest that observers and actors make different attributions about behavior, due to differences in their information processing perspectives. This attribution bias is related to two different factors. First, the observer has a different perspective than the actor. The attention of the actor is focused on his or her situation, but the attention of the observer is focused on the actor. Second, the observer has different available information than the actor. The actor knows more detail about the present situation, past situations, and his or her intention. The observer has self-knowledge about his or her own predicted behavior and how he or she has observed others behave in similar situations. Thus, "there is a pervasive tendency for actors to attribute their actions to situational requirements, whereas observers tend to attribute the same actions to stable personal dispositions" (Jones \& Nisbett, 1987, p. 80). Simply put, the actor attributes the cause to the situation and the observer attributes the cause to the actor's personal characteristics. In terms of WFC, an employed parent might attribute poor work 
performance to a particularly difficult day at work. An observer, however, might attribute poor work performance to the employee's inability to balance family and work life.

\section{Attributions of Responsibility}

In addition to the influence of differing viewpoints between actors and observers, situational and personal factors are quite relevant in the process of assigning responsibility. Weiner claims that six distinctions are necessary to understand the responsibility process: personal versus impersonal causality; controllability versus uncontrollability; personal controllability versus responsibility; intention versus negligence; responsibility versus blame; and blame versus anger (Weiner, 1995). The first three comparisons are used to reach a decision regarding whether or not a person is responsible for an event.

To determine whether the cause is personal or impersonal, a human cause for an event must exist to assign responsibility for the event. Weiner (1995) suggests that if a rock falls onto a car, the rock caused the damage, but the rock is not responsible for the damage. Thus, if a situation causes an event, no responsibility is assigned. Next, the observer must establish whether the actor had control over actions that lead to an outcome before responsibility can be assigned. After deciding if the actor had control over the event, the observer must ascertain if the actor is responsible for the event. Personal controllability and responsibility differ in that "causes, such as the absence of effort or lack of aptitude, are or are not subject to volitional alteration. Responsibility, in contrast, refers to a judgment made about a person---he or she, 'should' or 'ought to have' done otherwise, such as trying harder, eating less, or paying more attention when driving" (Weiner, 1995, p. 8). Thus, even though a person causes an event, he or she may not be responsible for that event due to mitigating circumstances (e.g., an employee fails at a job, due to lack of effort because of a sick spouse's need for care). 
Rather than being an all-or-nothing decision, there are degrees of responsibility. Intention versus negligence is one comparison that is made to determine degree of responsibility. In terms of crime, this could be categorized as the distinction between murder and manslaughter. Outcomes that were reached intentionally lead to higher degrees of responsibility than those that were a result of negligence.

The two final distinctions are concerned with consequences of the judgments of responsibility. Weiner (1995) provides two potential reasons for separating responsibility from blame. First, "responsibility is affectively neutral, whereas blame conveys emotional negativity" (Weiner, 1995, p. 14). Second, a person might be responsible for an outcome, but receive little blame due to the small impact of the consequences. If the consequences have greater impact, blame is more likely even if responsibility remains the same. For example, consider two situations in which a coworker is not able to assist with a work task because of the need to leave work early to pick up his or her child. In the first situation, only you and the coworker have been assigned to complete the task, thus you have to complete the entire task by yourself. In the second situation, you, the coworker, and two other people have been assigned to complete the task. Thus, you still have assistance in completing the project. In the first situation, you would most likely attribute more blame to your coworker than in the second situation, even though responsibility would remain constant. Thus, blame seems to be based on the impact of the consequences, but the same does not hold for responsibility. Finally, Weiner (1995) proposes that blame is a combination of responsibility and anger.

The Emotional Repercussions of Judgments of Responsibility (Weiner, 1995, p. 16)

"Anger is an accusation, or a value judgment, that follows from the belief that another person "could and should have done otherwise"." (Weiner, 1995, p. 17). When anger exists, it 
can link thoughts and action, driving one to be self-protective or to retaliate. Weiner (1995) also states that anger can be mitigated when impersonal causality, lack of control, or mitigating justifications exist. In such circumstances, the actor is less likely to be seen as responsible for the outcome, and the resulting emotion may be sympathy. Consider the case of the coworker who cannot assist with a task because of the need to leave work early to pick up his or her child. If the need to leave early is a result of poor planning, the observer may respond with anger. Anger in the workplace can result in different short-term consequences, such as constructive behaviors to resolve the situation, emotional withdrawal from the offender, and/or illegitimate or legitimate punishment of the offender (Booth \& Mann, 2005). Performance evaluation ratings are a means by which an angered individual can punish an offender.

The case of the coworker who cannot assist with a task because of the need to leave work early to pick up his or her child can be considered from another perspective. For example, if the need to leave early was based on the child having an emergency, the observer may respond with sympathy. These differences in emotions yield different reactions on the part of the observer. One potential reaction to sympathy is prosocial behavior.

Prosocial behavior is a superordinate category of behavior that is defined as "voluntary behavior intended to benefit another" (Eisenberg \& Fabes, 1991) and includes behaviors such as helping, sharing, and comforting. Eisenberg and Fabes (1991) specify that prosocial behaviors can be motivated by concerns that are egoistic, practical, other-oriented, or moral. Altruistic behaviors include behaviors that address the latter two concerns (practical and other-oriented) (Eisenberg \& Fabes, 1991). Prosocial behavior can arise from the superordinate category of vicarious emotional responses, which are defined as emotional reactions "induced by the apprehension of another's emotional state or condition" (Eisenberg \& Fabes, 1991, p. 35). This 
superordinate category includes empathy, which "frequently is defined as a vicarious emotional response that is identical or very similar to that of the other person" (Eisenberg, 1986). For example, when someone else feels sad, an empathetic responder would relate to this sad person and feel sad as well. Another vicarious emotional response is sympathy, which involves feeling sorrow or concern for another person (Eisenberg, 1986). Personal distress differs from sympathy and empathy, in that it "is an aversive reaction, such as anxiety or discomfort, to another's state that leads to the self-focused egoistic motivation of alleviating one's own aversive state" (Batson, 1987)

To describe the process of engaging in prosocial behavior, Dovidio, Piliavin, Gaertner, Schroeder, and Clark (1991) propose the arousal: cost-reward model, which entails two separate parts that influence prosocial behavior. In the first step, an observer experiences arousal due to another's need. The observer is then motivated to reduce the arousal. In the second step, an observer must consider the cost and reward for helping and not helping the person with need. Variation in arousal can yield variation in cost and reward, and vice-versa. Costs for helping may include effort, danger, and missed opportunities for rewards. Rewards for helping may involve "feelings of efficacy, admiration from others, fame, and awards" (Dovidio et al., 1991, p. 92). In addition to the influence of potential costs and rewards on helping decisions, attributions made about the individual who needs help determines whether or not help is distributed. How Does Attribution Theory Explain Differences in Reactions?

The decision regarding whether or not to help an individual in need of help follows the following chain:

Need for help $\rightarrow$ causal attribution $\rightarrow$ judgment of causal controllability $\rightarrow$ responsibility inference $\rightarrow$ anger and sympathy $\rightarrow$ social conduct (Weiner, 1995, p. 146) 
First, the observer must notice that a person needs help. Then the observer must decide whether or not this person caused the situation that required help. Next, the observer must determine whether the individual had control over the situation. After considering cause and control, the observer must consider mitigating circumstances. If cause and control exist, and if mitigating circumstances do not explain the outcome, the observer assumes the actor is responsible for his or her plight, and experiences anger. However, if the actor is not personally responsible for his or her situation, does not have control over the event, or if mitigating circumstances can explain the event, the observer experiences sympathy. When the observer experiences anger, the observer is more likely to punish, rather than help, the actor. In contrast, sympathy leads to helping decisions.

Rudolph, Roesch, Greitemeyer, and Weiner (2004) conducted a meta-analytic review of help giving and aggression, using an attributional perspective as a framework. They examined 64 studies to determine which of four models best explained the relationship between controllability/responsibility, sympathy, anger, and help giving/aggression. The model that best fit the data indicated sympathy and anger as mediators between controllability/responsibility and help giving/aggression. Thus, they found no direct link between controllability and help giving; emotion served as a mediator between these two factors. Controllability was negatively related to sympathy and positively related to anger. Sympathy was positively related to help giving; anger was negatively related to help giving. Thus, if an actor had control over the situation that negatively impacted the observer, this would elicit anger on the part of the observer. In turn, the observer would be less likely to help the actor. In addition to finding support for their model, Rudolph and colleagues (2004) found that this relationship holds true for real events and simulated data (p. 838). 


\section{Current Study}

As shown in the studies that have been described thus far, employees who have more work-family conflict report more negative workplace and family experiences than those who experience less work-family conflict (Beutell \& Wittig-Berman, 1999; Burke, 1994; Carlson et al., 2000; Carlson \& Perrewé, 1999; Frone et al., 1997; Good et al., 1996, 1988; Goff et al., 1990; Higgins et al., 1992). Fortunately, social support can remedy some of these issues. Research has shown that employees with and without children are perceived differently in the workplace, such that parents are perceived as less agentic and committed to the job than nonparents (Fuegen et al., 2004), In addition, studies have suggested that men and women who behave similarly have different workplace experiences. For instance, employed women are viewed more negatively than employed men when they behave assertively (Costrich, Feinstein, Kiddler, Marecek, \& Pascale, 1975; Eagly, Makhijani, \& Klonsky, 1992). Research has also demonstrated that gender interacts with parental status, to the benefit of male parents (Cuddy et al., 2004; Fuegen et al., 2004). In addition, evidence has been provided that employed mothers are viewed as "bad mothers" if they choose to work (Gorman \& Fritzsche, 2002). Finally, attribution theory proposes that individuals who are perceived as responsible for their own problems are less likely to receive help and are more likely to be the targets of aggression than those who have no control over their problems (Weiner, 1995). Thus, employees who are perceived to juggle work and family roles may receive less social support and are more likely to be the targets of aggression (i.e., negative performance appraisal ratings) than those who are not perceived as having to juggle multiple roles, as a person's decision to work, despite family responsibilities, is perceived as controllable. 
The purpose of this study was to empirically examine the impact of an individual's gender, reported family interference with work, and control over a situation on the help received by this individual, performance evaluation ratings made about the individual and willingness of another person to work with the individual on future projects. In this experiment, participants had the opportunity to help a target individual, work with the target individual on a team task, evaluate the target individual on his or her performance, and then indicate their interest in working with this individual in the future. The target individual was a confederate of the researcher who was tardy to the experiment. The target individual's gender, reason for tardiness (family related vs. self related), and control over the reason for the tardiness were manipulated. This study allowed empirical examination of the influence of employee gender, reported family interference with work, and control over a situation, as well as the interactions between these variables, on helping behaviors, evaluation ratings and intent to interact with the target individual in the future. Based on the sex role theory, predictions made by attribution theory, and research that has investigated the impact of gender and parental status on employment decisions, I proposed the following hypotheses:

Hypothesis one. Based on attribution theory, people without control over the reason for the tardiness were expected to receive higher evaluation ratings and were more likely to receive social support than people with control over the reason for the tardiness.

Hypothesis two. Based on attribution theory, it was expected that people who were late for self-related reasons would receive higher evaluation ratings and would be more likely to receive social support than people who were late for family-related reasons, as a person's choice to work despite family responsibilities is perceived as controllable. 
Hypothesis three. Sex role theory suggests that women who behave assertively in the workplace are rated less positively than men. Thus, it was expected that men would receive higher evaluation ratings and would be more likely to receive social support than women.

Hypothesis four. It was proposed that gender would interact with family responsibilities, as follows. Women who were tardy for a family-related reason would receive lower evaluation ratings and less social support than women who were tardy for a self-related reason. As predicted by hypothesis three, men's ratings were still expected to be higher than women's ratings, despite the reason for the tardiness. Men's ratings and received social support were expected to be negatively impacted when tardiness was the result of family-related reasons, but not as great as the impact experienced by women.

This interaction was expected because research has shown that parental status has a differential impact on employment decisions, dependent upon parent gender, to the benefit of male parents. For example, male parents and male non-parents were not perceived differently, in terms of competence (Cuddy et al., 2004), and were equally likely to earn hiring recommendations (Cuddy et al., 2004; Fuegen et al., 2004). However, employed mothers were perceived as less competent and were less likely to earn hiring recommendations than employed women without children (Cuddy et al., 2004; Fuegen et al., 2004).

Research has demonstrated that increases in social support are associated with decreases in WFC (Burley, 1994; Carlson \& Perrewé, 1999; Goff et al., 1990; Nielson et al., 2001). However, no studies were found that empirically examined differences in receipt of social support. Hence, this study empirically examined the impact of control over a workplace situation (tardiness), employee gender, and type of conflict (reason for the tardiness was family-related vs. 
self-related) on social support and performance evaluation ratings. This research provides a relevant contribution to the WFC literature and potentially to workplace practices. 


\section{CHAPTER THREE: METHODOLOGY}

\section{Participants}

Participants were recruited using the University of Central Florida Psychology Department Research Experience system. Two hundred forty-five participants earned two points of extra credit for completing the study. One hundred twenty-one of those participants earned an additional point of extra credit by completing an online questionnaire that was posted as a separate, unrelated study (see Appendix $\mathrm{C}$ for the Informed Consent Form). Participants had a mean age of 18.72 years $(S D=1.64)$ and were $63 \%$ female. $59 \%$ of the participants defined themselves as Caucasian/White, $13 \%$ as African-American, 13\% as Hispanic, 5\% as Asian, and $10 \%$ as Mixed/Other.

Design

The study employed a 2 × 2 × 2 independent factorial design in which control (control versus no control), type of work conflict (self-related versus family-related), and teammate gender were manipulated. The eight conditions were rotated, such that the first participant received condition $\mathrm{A}$, the second participant received condition $\mathrm{B}$, and so on. The dependent variables were provided social support (i.e., a participant's choice to help or not help a teammate) and participants' performance evaluation ratings about the teammate.

\section{Measures}

Social support. Social support was measured by a participant's decision to help, or not help, a tardy teammate by completing an individual word-sort task for the teammate (confederate). First, the participant completed the word-sort task for himself/herself. The participant categorized a list of fifty words into one of five categories (see Appendix D). If the participant chose to help the teammate, a different set of words and categories was used for the second sort task (see Appendix E). 
Performance evaluation rating. See Appendix F. An evaluation form developed for the purposes of this study was used to assess participants' opinions about the teammate and the teammate's performance. The first two items asked participants to identify confederate gender and major, as a manipulation check. This measure includes items such as, "My teammate was a quick learner" and "My teammate did less work than me" (reverse-coded).

Task evaluation rating. See Appendix G. Participants' opinions about the study were measured by a rating form that was developed for the purposes of this study. The measure includes items such as, "I enjoy word-based tasks, in general" and "The task was boring." (reverse-coded).

Demographic survey. See Appendix H. The demographic survey includes questions about age, gender, family status (e.g., marital status, parental status), and employment status.

Work-Family Conflict. See Appendix I. Work-family conflict (WFC) was measured by Carlson, Kacmar, and Williams' (2000) WFC measure, which assesses time-, strain-, and behavior-based WIF and FIW. An example of a time-based FIW is "The time I spend with my family often causes me not to spend time in activities at work that could be helpful to my career." An example of a strain-based WIF item is "Due to all the pressures at work, sometimes when I come home I am too stressed to do the things I enjoy.” An example of a behavior-based WIF item is "The behaviors I perform that make me effective at work do not help me to be a better parent and partner at home." The scale has shown internal consistency, discriminant validity, and invariance of the factor structure across samples and the reported coefficient alpha values for all subscales are .79 or higher (Carlson et al., 2000). Further, the subscales differentially relate to the multiple antecedents and outcomes of WFC, which indicates potential predictive validity (Carlson et al., 2000). 
Attitudes toward teamwork. See Appendix J. Attitudes toward teamwork were measured by a questionnaire that includes items selected from a survey administered by Pfaff and Huddleston (2003) to determine students' attitudes toward teamwork and the entire Lone Wolf Scale (Barr, Dixon, \& Gassenheimer, 2005). Pfaff and Huddleston (2003) found that absence of a "free rider" on a team was predictive of attitudes toward teamwork (as indicated by their survey). Internal consistency reliability estimates for the subscales from which the attitudes toward teamwork items were selected were .70 or higher. Barr, Dixon, and Gassenheimer (2005) reported that results of confirmatory factor analysis indicated that the lone wolf construct exhibited discriminant validity, as it was distinctly different from trust, autonomy, and team orientation. Coefficient alpha for the lone wolf measure was .78 (Barr et al., 2005). Examples of items from these scales are, "I still like working in groups, despite the fact that I've had to deal with members who don't contribute." and "Working with others is a hassle." (reverse-coded).

Agreeableness. See Appendix K. Agreeableness was measured with the 20 -item agreeableness subscale of the International Personality Item Pool. Agreeableness is depicted as a dimension of interpersonal tendencies; the agreeable person is described as "fundamentally altruistic. He or she is sympathetic to others and eager to help them, and believes that others will be equally helpful in return" (Costa \& McCrae, 1992). Agreeableness is assessed with items such as, "Take time out for others." and "Have a good word for everyone." The internal consistency reliability estimate for this measure is .88 (International Personality Item Pool, n.d.).

Prosocial behavior tendencies. See Appendix L. The Prosocial Personality Battery (PSB) was used to measure prosocial behavior tendencies. This measure assessed two factors related to prosocial behavior: other-oriented empathy and helpfulness. Other-oriented empathy is assessed with items such as "When I see someone being taken advantage of, I feel kind of protective 
towards them." Helpfulness is assessed by items such as "I have allowed someone to go ahead of me in a line (e.g., supermarket, copying machine, etc.)" In validation efforts, the coefficient alpha values for other-oriented empathy and helpfulness were both in excess of . 80 and were positively related to helping decisions, volunteering, and employee prosocial behaviors (Penner, Fritzsche, Craiger, \& Freifeld, 1995).

Sex role measure. Perceived sex roles were assessed with the Bem Sex Role Inventory (Bem, 1974) (see Appendix M). Participants rated the correspondence of their personality and behaviors with each of 60 adjectives/phrases (e.g., 'sympathetic', 'acts like a leader', 'unsystematic') by using a seven-point scale. These adjectives/phrases differ in terms of perceived masculinity and femininity. The results of this measure are used to determine how an individual perceives him or herself in terms of masculine and feminine sex roles. In validation efforts, the reported coefficient alpha values for the subscales were .86 , and .80 , respectively. Validity evidence shows that the femininity and masculinity scales are associated with genderrelated behavior (Lippa, 1985).

\section{Procedure}

The study was listed as an hour-long team study, which was administered by two experimenters, one who acted as the experimenter for the participant (Experimenter 1) and another who acted as an experimenter for the teammate and as the teammate (Experimenter 2). The title of the team study was listed as "An assessment of the use of instant messaging (IM) software to complete two-person tasks."

Participants were instructed to arrive at the laboratory at the designated study start time. The participant reviewed the informed consent script (see Appendix N) and participated in the individual word-sort task and then recalled as many words as possible from that task. While the 
participant was completing the word-sort task, or shortly after the completion of the word-sort task, Experimenter 2 came to the lab door. Experimenter 2 provided the participant with a narrative, which was based on the condition for the experimental session. Participants were randomly assigned to one of eight experimental conditions, in which confederate gender (male, female), reason for tardiness (family-related, self-related), and confederate's control over the situation (no control/emergency physician visit, control/planned physician visit) were manipulated (see Appendix $\mathrm{O}$ for the experimenter script, which provides the script for each condition). For example, in the condition where the teammate was tardy for a self-related reason and had control over the situation, the dialog between the experimenters proceeded as follows:

Experimenter Two, "Your teammate, Jennifer, just called and she'll be here in 10 minutes. She's running late because she had a doctor's appointment that she forgot about. We will start the team part as soon as she gets here"

Experimenter One to Experimenter Two, "Do you think it would be okay for her/him (participant) to do Jennifer's sort?"

Experimenter Two, “That would work, because it is a different set of words and it won't affect the team score. Otherwise, Jennifer will have to stay after to do it. But it is up to you...it doesn't make a difference to us."

Both Experimenter 1 and Experimenter 2 then asked if the participant wanted to help the teammate (confederate) by completing the individual word-sort task for the teammate (confederate). The participant's decision regarding whether or not to complete the individual word-sort task for the teammate (confederate) served as a measure of social support. If the participant declined the opportunity to help the teammate, Experimenter 1 left the room and said he/she would return when the teammate arrived. If the participant chose to help the teammate, 
Experimenter 1 administered the second individual word-sort task and recall task, then left the room and said he/she would return when the teammate arrived.

Seven to eight minutes later, Experimenter 1 returned to the lab and announced that the teammate (confederate) had arrived at the other research lab. Experimenter 1 signed into the IM system and typed "We are ready." Experimenter 1 informed the participant that the teammate would introduce himself/herself and that the participant should then introduce himself/herself by providing a name, major, and what he/she liked to do for fun. The teammate (confederate) always stated that he/she enjoyed spending time with his/her daughter in the introduction, to avoid confounding parental status with the independent variables. In addition, the teammate (confederate) apologized for being tardy, and reiterated the reason for tardiness. Experimenter 1 then described the twenty questions game and asked the participant to provide the category for the first word on the list.

The team task was an IM version of the 20 questions game. The variant of the game was "Animal, Vegetable/Fruit, Transportation." The words for the game were obtained from a list of ESL/EFL Basic vocabulary word lists (Kelly \& Kelly, n.d.). Prior to conducting the experiment, the research assistants who acted as experimenters in the study completed extensive testing with the words that were identified for use in the 20 questions game. Some of the words in the initial list were replaced with words that generated less confusion. For example, pumpkin was removed as it was often difficult for individuals to identify if it was a fruit or a vegetable.

The participant and the confederate each had a list of 25 words and alternated turns as questioner or responder. At the start of the each round, the responder told the questioner the category for the target word. The goal of the game was for the questioner to determine the word, using as few yes/no questions as possible. For example, suppose the word was elephant. The 
answerer would start by saying, "Animal." The questioner could ask questions such as, "Is this animal a pet?" The question/response activity continued until the object was identified, or until 20 questions were asked. Experimenter 1 monitored the session and recorded the number of questions asked by the questioner. When 20 questions were asked and the word had not been identified, the participant and teammate (confederate) were instructed to proceed to the next word on the list, and change roles (former questioner became responder). When the teammate (confederate) was the questioner, he/she asked the same question sets for the target words, to hold performance constant across conditions. The list of words that participants were asked to solve is provided in Appendix P. The list of words that teammates (confederates) were asked to solve, as well as the questions that they asked to arrive at the solution are provided in Appendix Q.

The participant was informed that the goal of the game was to identify as many words on the list as possible. The participant was told that the top three scorers in this study would receive a $\$ 50$ gift card. This was expected to increase performance motivation among participants. After completing the team task, the participant was asked to recall as many of the words as possible from the IM task. Then, the participant completed the teammate and task evaluations.

After the participant completed the post-task measures, Experimenter One completed a follow-up questionnaire to determine if the participant attended to the study details (teammate gender, reason for tardiness, and control over tardiness), which served as an additional manipulation check. In addition, this questionnaire was used to assess the participants' thoughts about the purpose of the study and to determine if the participants were aware of the deception (see Appendix R). Experimenter One then provided a full debriefing about the purpose of the experiment (see Appendix S), in which participants were informed of the true purpose of the 
study and provided with a reason for the need for deception. As part of the debriefing, participants were also informed that they may have completed an online questionnaire on the Psychology Department Research Experience system earlier in the semester, and that the data from the online questionnaire would be used in the current study. My contact information, as well as that of Dr. Barbara Fritzsche (my advisor) was provided, in the event that participants had any questions after completing the study. 


\section{CHAPTER FOUR: RESULTS}

Prior to testing hypotheses, I examined participants' responses to the debriefing questions and manipulation check. I eliminated the responses of participants who suspected that the teammate was a confederate of the study $(n=12)$ or felt that the experimenter was role playing $(n=12)$. I also eliminated data from those participants who did not pass the majority of the manipulation check items $(n=7)$, leaving a final sample size of 218 for examining the hypotheses.

Before conducting further analyses, the data were screened by following Tabachnick and Fidell's (2001) recommendations for assessing data quality. Data were checked and corrected and missing data was not an issue. No unexpected outliers were found. Performance evaluation ratings data were fairly normally distributed. Data were linear and homogeneity of variance was evidenced by Levene's Test of Equality of Error Variances, $F(7,210)=.09, p=.99$.

To assess the relationships between the measures, I performed correlation analyses for the continuous variables and a one-way analysis of variance to analyze the impact of participant gender. Table One provides the means, standard deviations, internal consistency reliability coefficients, and intercorrelations for the measures (see Appendix T). Internal consistency reliability coefficients were .78 or higher for all measures, except for task ratings $(\alpha=.66)$. Findings are discussed in terms of work-family conflict (WFC), evaluation ratings, participant gender and reported sex role, and additional interesting findings between the individual differences measures.

Four of the six WFC subscales were correlated with task ratings, as follows: time-based WIF $(r=-.12, p<.05)$, time-based FIW $(r=-.23, p<.05)$, strain-based FIW $(r=-.22, p<.05)$, behavior-based WIF $(r=-.21, p<.05)$. In addition, three of the six WFC subscales were correlated with attitudes toward teamwork, as follows: time-based FIW $(r=-.24, p<.05)$, strain- 
based FIW $(r=-.21, p<.05)$, and behavior-based FIW $(r=-.28, p<.01)$. Thus, people who reported higher levels of the specified types of WFC rated the task lower and had more negative attitudes toward teamwork than individuals who reported less work-family conflict. In addition to WFC, femininity and agreeableness were positively correlated with attitudes toward teamwork $(r=.24, p<.05$ and $r=.39, p<.01$, respectively). Thus, as reported femininity and agreeableness increased, so did attitudes toward teamwork.

Evaluation ratings were positively correlated with task evaluation ratings $(r=.17, p<$ $.05)$; people who rated their teammates positively also rated the team task positively. Evaluation ratings were also positively correlated with helpfulness $(r=.24, p<.05)$ as measured by the Prosocial Personality Battery (PSB). Thus, people who had acted in helpful ways in the past rated their teammates higher than did individuals with lower self-ratings for helpfulness.

Gender was related to femininity $(F(1,103)=17.17, p=.00)$, such that women $(M=$ $102.30, S D=12.86)$ had higher scores than men $(M=91.87, S D=11.52)$. Mean scores for masculinity did not differ significantly between men $(M=97.92, S D=15.57)$ and women $(M=$ $96.55, S D=14.61, F(1,103)=.20, p=.65)$. Further, masculinity was correlated with femininity $(\mathrm{r}=.33, \mathrm{p}<.01)$. Participant gender and reported sex roles were also related to agreeableness. Women $(M=79.99, S D=9.93)$ reported more agreeable tendencies than men $(M=73.34, S D=$ $9.19, F(1,103)=11.45, p=.00)$. In addition, agreeableness was correlated with masculinity $(r=$ $.20, p<.05)$ and femininity $(r=.69, p<.01)$. Similar to findings for participant gender and agreeableness, the femininity-agreeableness correlation was stronger than the masculinityagreeableness correlation $(t=-5.75, p<.01)$.

Participant gender and sex roles were also related to prosocial personality tendencies. Women $(M=132.79, S D=13.46)$ scored higher than men $(M=124.76, S D=13.01)$ on other- 
oriented empathy $(F(1,103)=8.83, p<.01)$. Scores on other-oriented empathy were positively correlated with agreeableness $(r=.63, p<.01)$, masculinity $(r=.26, p<.01)$, femininity $(r=$ $.61, p<.01)$, helpfulness as measured by the $\operatorname{PSB}(r=.24, p<.05)$, and attitudes toward teamwork ( $r=.25, p<.05)$, such that as scores on other oriented-empathy increased, scores on all of the other measures increased. The correlation between femininity and other-oriented empathy was stronger than the correlation between masculinity and other-oriented empathy ( $t=-$ 3.73, $p<0.1)$. Helpfulness as measured by the PSB was positively correlated with femininity $(r$ $=.26, p<.01)$; helpfulness scores increased as femininity scores increased.

After reviewing all of the correlations, the main hypotheses of the study were analyzed. $94 \%$ of the participants chose to provide social support to their teammate by completing the teammate's card sort task, so the teammate would not have to complete the task after the scheduled experiment session. Given the lack of variance in helping behavior, this was not a suitable dependent variable. Thus, the hypotheses were analyzed with a $2 \times 2 \times 2$ analysis of variance in which the dependent variable was performance evaluation ratings about the teammate. The independent variables were control over the reason for tardiness (unexpected need to visit the physician versus forgotten physician's appointment), type of conflict (selfrelated versus family-related reason for tardiness), and teammate gender. The examination of the specific hypotheses and the findings are discussed below.

\section{Hypothesis One}

Based on attribution theory, people without control (unplanned physician's visit due to illness) over the reason for the tardiness were expected to receive higher evaluation ratings than people with control (forgotten physician's appointment) over the reason for the tardiness. The results of the ANOVA were not statistically significant $\left(F(1,210)=.92, p=.34, \eta^{2}=.00\right)$. 
People who were tardy because they were sick and made an unplanned visit to the doctor's office did not receive statistically different evaluation ratings $(M=52.33, S D=6.40)$ than those who were running late because they forgot about a scheduled doctor's appointment $(M=51.55, S D=$ 6.41). Thus, hypothesis one was not supported.

Hypothesis Two

Based on attribution theory, people who were late for self-related reasons were expected to receive higher evaluation ratings than people who were late for family-related reasons. This was expected because a person's choice to work, despite family responsibilities, is perceived as controllable. The results of the ANOVA were not statistically significant $(F(1,210)=2.64, p=$ $\left..11, \eta^{2}=.01\right)$. This hypothesis was not supported, as results indicated that the ratings for people who were late for a family-related reason $(M=52.62, S D=6.21)$ did not differ significantly from those who were late for a self-related reason $(M=51.27, S D=6.54)$. Therefore, hypothesis two was not supported.

Hypothesis Three

Sex role theory suggests that women who behave assertively in the workplace are rated less positively than men. Thus, it was expected that men would receive higher evaluation ratings than women. The results of the ANOVA were not statistically significant $(F(1,210)=.71, p=$ $\left..40, \eta^{2}=.00\right)$. Evaluation ratings did not differ for men $(M=51.58, S D=6.24)$ and women $(M=$ $52.28, S D=6.57)$. Accordingly, hypothesis three was not supported.

\section{Hypothesis Four}

It was proposed that gender would interact with family responsibilities. Specifically, women who were tardy for a family-related reason would receive lower evaluation ratings than women who were tardy for a self-related reason. Men's ratings and received social support were 
expected to be negatively impacted when tardiness was the result of family-related reasons, but not as great as the impact experienced by women.

The interaction between gender and reason for tardiness was not statistically significant $\left(F(1,210)=.09, p=.77, \eta^{2}=.00\right)$. Men who were tardy for a family-related reason $(M=52.11$, $S D=6.05)$ did not receive different evaluation ratings than men who were tardy for a self-related reason $(M=51.04, S D=6.44)$. Like the men, women's ratings did not differ significantly if they were late for a family-related reason $(M=53.15, S D=6.38)$ or a self-related reason $(M=51.49$, $S D=6.69)$. Thus, hypothesis four was not supported.

\section{Exploratory Analyses}

To examine the impact of participant gender, I conducted an additional analysis of variance with participant gender, control, type of conflict and teammate gender as independent variables and performance evaluation ratings as a dependent variable. Homogeneity of variance was evidenced by Levene's Test of Equality of Error Variances, $F(15,197)=.359, p=.99$.

There was a main effect for control $\left(F(1,197)=4.24, p=.04, \eta^{2}=.02\right)$, such that people who had control over the tardiness $(M=58.43, S D=6.93)$ received lower evaluation ratings than people who did not have control over the tardiness $(M=60.09, S D=6.91)$. Further, there was a main effect for type of conflict $\left(F(1,197)=3.49, p=.06, \eta^{2}=.02\right)$, such that people who were late for a family-related reason received higher evaluation ratings $(M=60.09, S D=6.85)$ than those who were late for a self-related reason $(M=58.42, S D=6.98)$. However, these findings must be interpreted in light of a three-way interaction between participant gender, teammate gender, and type of conflict $\left(F(1,197)=3.58, p=.06, \eta^{2}=.02\right)$. Figure three (Appendix U) provides a graphical representation of this interaction. As evidenced by an LSD post-hoc analysis $(p=.01)$, men provided higher evaluation ratings to female teammates who were late for a child- 
related reason $(M=63.84, S D=6.68)$ than to those who were late for a self-related reason $(M=$ $58.21, S D=7.94)$ 


\section{CHAPTER FIVE: CONCLUSION}

None of the hypotheses were supported in this study. However, exploratory analyses that included participant gender as an independent variable showed that people without control (unplanned physician's visit due to illness) over the reason for the tardiness received higher evaluation ratings than people with control (forgotten physician's appointment) over the reason for the tardiness. This is consistent with attribution theory, which suggests that people who don't have control over a situation are more likely to receive help than those who do have control (Weiner, 1995). Further, people who don't have control over a situation are less likely to be the targets of aggression than people who do have control over a situation (Weiner, 1995). In this study, participants may have been more likely to provide help to and less likely to exhibit aggression toward teammates by providing higher evaluation ratings to those who did not have control over the reason for tardiness than to those who had control over the reason for tardiness.

Further, exploratory analyses showed that women with family conflict benefited when rated by male participants, contrary to the predictions based on attribution and sex role theory. When participant gender was added as an independent variable, a significant three-way interaction between participant gender, teammate gender, and type of conflict (self-related versus family-related) emerged. Men rated female teammates who were late for a family-related reason higher than those who were late for a self-related reason. These findings were not in the predicted direction, but may be explained by the context of the study and Cuddy, Fiske, and Glick's (2004) stereotype content model (SCM), in which members of groups who are perceived as high on warmth and high on competence are the in-group and typically receive assistance from and cooperation with other groups. A woman who attends school, participates in research for extra credit, and takes her child to the doctor's office might be perceived as warmer than a woman who visits the doctor for a self-related reason, simply because the former is attending to 
the needs of her child. Even though both women are competent, the difference in warmth may explain differences in the evaluation ratings provided by men. Recent research on the treatment of pregnant women is consistent with these findings. For example, the results of a field-based study showed that store employees exhibited more benevolent behaviors toward pregnant than non-pregnant customers (pregnancy was manipulated by wearing a pregnancy prosthesis) (Hebl, King, Glick, Singletary, \& Kazama, 2007). However, when the same women applied for jobs in the stores, the store employees exhibited more hostile behaviors when the applicants were pregnant than when the applicants were not pregnant. Thus, as long as pregnant women were acting according to expected social roles (i.e., customers, not job applicants), they were treated benevolently. In this case, men may have considered caring for one's child and attending school as adhering to a non-threatening social role, and thus treated women benevolently. The findings may have been different if the teammates in this study were applying for a job and late for a family-related reason.

Despite the fact that none of the hypotheses were supported, several interesting correlations were present in this study, specifically those related to work-family conflict (WFC), evaluation ratings, gender and sex roles, and prosocial behavior tendencies (as assessed by the PSB). Individuals with higher levels of WFC rated the task lower than individuals with lower levels of WFC. Specifically, four of the six WFC subscales were negatively correlated with task evaluation ratings (time-based WIF, time-based FIW, strain-based FIW, and behavior-based WIF). Thus, as conflict increased due to family-related and work-related time requirements and stress that carried from the family to the work environment, participants' task evaluation ratings decreased. In addition, participants were likely to provide low task evaluation ratings if behaviors that were effective at work were not applicable at home. In this situation, the need to 
use one's personal time to meet school requirements (participation in research projects for psychology class credit), along with stress that crosses from the home to the school environment, may have caused a conflict between the roles of family-member and student. This conflict may have resulted in a participant rating a task negatively, due to the time it detracted from attending to the needs of the home environment. The task ratings may have been further impacted by behavior-based WIF, as the skills one was practicing in the study environment (i.e., a 20 Questions game) were not helpful in the home environment (i.e., behavior-based WIF).

In addition, individuals with higher levels of WFC had more negative attitudes toward teamwork than individuals with lower levels of WFC. Three of the six WFC subscales were negatively correlated with attitudes toward teamwork (time-based FIW, strain-based FIW, and behavior-based FIW). People who had more family responsibilities and stresses from the home environment that carried into the work environment had more negative attitudes toward teamwork than people with less family-work stress and family responsibilities. It is possible that such individuals perceived that they could have made better use of their available time than participating in research-based teamwork. Thus, it also is logical that individuals would not have valued teamwork when behaviors from the family environment were not helpful in the work environment.

Evaluation ratings and helpfulness (as measured by the PSB) were related, such that people who had higher ratings on helpfulness gave higher evaluation ratings than those with lower ratings on helpfulness. People with high helpfulness scores have reported past helping behaviors and are more likely to engage in prosocial employee behaviors (Penner et al., 1995). Thus, people who scored high on helpfulness may have been more likely to help a teammate by providing higher evaluation ratings for the teammate than people who scored low on helpfulness. 
Several interesting and expected gender and sex-role related findings were present. Women reported more feminine tendencies than men. However, men and women did not differ in terms of reported masculinity. These results may indicate a less gender-role-typed sample, at least in terms of masculine attributes, than what Bem (1974) found in her original research. Consistent with previous research on gender differences and personality, women were more agreeable than men (Costa, Terracciano, \& McCrae, 2001) and the relationship between agreeableness and sex role was stronger for femininity than masculinity (Lippa, 1991). In addition, women had higher other-oriented empathy scores than men. Similar to the findings for agreeableness, the relationship between femininity and other-oriented empathy was stronger than the relationship between masculinity and other-oriented empathy. Further, increases in femininity scores were associated with increases in attitudes toward teamwork and helpfulness scores on the PSB. The femininity subscale includes items such as sympathetic, sensitive to the needs of others, understanding, and yielding, so perhaps individuals who see themselves in this light were more likely to express other-oriented empathy (Bem, 1974). Societal expectations that women should engage in communal behaviors, such as friendliness, unselfish acts, concern for others, and emotional expressiveness, may explain the stronger relationship between femininity and other-oriented empathy, helpfulness, and attitudes toward teamwork (Eagly, 2000).

Prosocial behavior tendencies (as measured by the PSB) were related to other constructs in a manner that is consistent with existing research. As other-oriented empathy increased, agreeableness also increased. This outcome is logical, as individuals who score high agreeableness are described as altruistic, sympathetic to others, and eager to help (Costa \& McCrae, 1992). Higher levels of other-oriented empathy were also associated with more positive attitudes toward teamwork. People who score high on other-oriented empathy are more likely to 
be concerned with the welfare of others than those who score low on other-oriented empathy (Penner et al., 1995). Thus, individuals who score high on other-oriented empathy may have an attitude that is more conducive to teamwork than those who score low on other-oriented empathy. Similar to validation findings for the PSB scale, the other-oriented empathy and helpfulness subscales were positively related (Penner et al., 1995).

\section{Limitations}

In this study, $94 \%$ of participants provided social support to their teammates, which made it impossible to determine the impact of the manipulations (control, gender, and type of conflict) on social support. The lack of variance in social support could be explained by a few factors. First, providing social support was very easy. It entailed completing a simple and short (fewer than five minutes) word sort task. The experimenters who administered the study reported that the participants acted as if helping the teammate by completing an extra word sort task was no big deal, and did so without resistance. This suggests that the costs of helping and the cost of the teammate's tardiness were not great enough to prevent social support. Costs for helping include effort, danger, and missed opportunities for rewards (Dovidio et al., 1991). Effort was the participant's only cost in this study and even so, the effort required was not that substantial. The teammate tardiness did not generate missed opportunities for rewards, as participants were informed they would have sufficient time to complete the team task to compete for the prize (i.e., the $\$ 50$ gift card). Demand characteristics may also have influenced participants' helping decisions. They may have perceived that completing the task was a favor for the researcher, rather than a favor to the teammate. Further, participants may have provided social support because they did not want to be perceived as an unhelpful person by the researcher. Future research to examine the impact of WFC on social support could be designed to better control for 
demand characteristics and require a combination of high effort and a likelihood of missed opportunities for helping (e.g., the teammate asking the participant to return on a Friday or Saturday evening to complete the study).

Participants' demographic characteristics may have influenced the results of this study. On average, participants were 18 years old. Of the participants who provided demographic data, only four reported having children and less than half were employed (44\%) or in a committed relationship (45\%). Further, the average WFC subscale score for participants was 5.89 ( $S D=$ 2.76). The possible values for the WFC subscales range from 3-15, indicating that most participants in this study experienced relatively low WFC. Individuals with more family and work responsibilities may be more prone to attribution-based judgments about individuals with WFC than this sample, as they have more likely experienced the repercussions of their own and others' WFC. Given the fact that college samples are often used in empirical research, future studies of this nature could assess the impact of participants' perceptions of their parents' WFC on helping decisions and performance evaluations. Participants may not experience a great deal of WFC, but the extent to which their parents' WFC was negatively impactful (e.g., parents missed participants' school or extracurricular activities due to work demands) may influence their treatment toward individuals with WFC.

Further, participants worked with teammates on a one-time basis. In the work environment, individual performance varies and individuals work with coworkers for extended periods of time, often on several team projects, and compete for job opportunities and performance-related outcomes. It may be beneficial to determine if performance is related to control, gender, and type of work-conflict, such that poor performers are more negatively impacted than good performers. The impact of performance could be measured by varying 
performance feedback (e.g., informing participants that their team scored in the upper or lower $25 \%$ of all teams). After receiving the performance feedback, participants could complete an evaluation about their teammate and indicate preferences for working with the same teammate in future research. Future research could also be designed such that the teammates have repeated interactions, in which a relationship is established. This type of research would be helpful to determine the impact of relationship duration on social support and evaluations, when the needs for help are family-related.

Despite the differences between this sample and workplace populations in terms of age, WFC, and extent of teammate interaction, the general purpose of laboratory-based research is to test causal hypotheses, not "to determine the probability that a certain event will occur in a particular population” (Berkowitz \& Donnerstein, 1982). In this college-based sample, exploratory analyses revealed that teammate gender and type of conflict influenced participants' performance evaluation ratings about teammates. Thus, it is possible that performance evaluations may also differ on the basis of gender and WFC in less controlled environments (i.e., the workplace). Field-based research can be conducted to determine if such outcomes are present in the workplace. However, it must be noted that field-based research is also subject to limitations in external validity, as the differences between organizational settings can be "as large as the differences that exist between an organizational setting and a laboratory" (Dipboye \& Flanagan, 1979). For example, organizations with highly regulated hours and processes and those that offer flextime and encourage creativity in completing work requirements are quite likely to differ in degree of family-friendliness.

Finally, this research project focused on blatant rather than subtle discrimination. Participants were directly asked if they would like to provide social support, then made the 
choice to help (or not help) a teammate, and provided performance evaluation ratings about a teammate. Discrimination in the workplace also takes on less overt forms. For example, current research suggests that incivility is a form of modern discrimination in organizations (Cortina, 2008). Workplace incivility is defined as "low intensity deviant behavior with ambiguous intent to harm the target, in violation of workplace norms for mutual respect. Uncivil behaviors are characteristically rude and discourteous, displaying a lack of regard for others" (Anderson \& Pearson, 1999, p. 457). Accusations about someone's incompetence or talking over someone while he/she is speaking are examples of workplace incivility (Cortina, 2008). Ignoring an obvious need for social support may also fall under this category, as a potential helper could claim to be unaware of the need, given a busy day or large workload. Cortina (2008) reported that over $70 \%$ of respondents in samples of court employees, university employees, and law enforcement employees have experienced workplace incivility. Thus, workplace incivility may be a subtle form of discriminating against people who need social support. Future research could address the impact of subtle discrimination, such as workplace incivility, on the relationship between social support and WFC.

\section{Implications}

In this study, exploratory analyses showed that men provided higher performance evaluation ratings to women who exhibited a family-related conflict than to women who exhibited a self-related conflict. Thus, women with WFC got a break when they were evaluated by men. Given the large population of employees with family responsibilities who work in teambased settings, it is important to determine if the relationship between social support and WFC is similar to these findings for performance evaluation ratings and WFC. In other words, are coworkers more likely to provide social support to other coworkers with WFC than to those 
without WFC? Research has indicated that social support from mentors and coworkers can reduce WFC (Carlson \& Perrewé, 1999; Goff et al., 1990; Nielson et al., 2001). Thus, if social support is provided to employees who may need it the most, the negative impacts associated with WFC (decreases in family, job and life satisfaction, quality of family life, and physical health; increases in intention to quit one's job and workplace absenteeism) may be reduced.

Accordingly, future research should further explore the relationship between WFC and social support, taking into consideration the limitations of the current study. Efforts are underway in this area, given the recent design of a coworker informal work accommodations to family (C-IWAF) scale that can be used to assess behaviors that coworkers employ to assist each other in dealing with WFC (Jimenez, 2008). This scale could be used to address the extent to which a person's exhibited WFC affects received social support. If future research provides further evidence that coworker social support reduces the negative outcomes associated with WFC, then this would yield additional support for family friendly workplace policies and cultures.

In 2005, the U.S. Census Bureau reported that $60.7 \%$ of married couples with children younger than 18 years old were dual-earner families. $40 \%$ of employed parents report that they experience WFC at least some of the time (Galinsky et al., 1993). Despite the demands of work and family, the potential for resulting role-conflict, the negative work and family outcomes, and the notion that it is impossible to "have everything and do everything at the same time" (Winfrey, 2003), it is doubtful that we will ever stop trying. Thus, it is imperative to understand the impact of WFC and learn how to reduce it, to better life for all employees. With that understanding, organizations can take steps to create cultures and design systems that are supportive for all employees, regardless of gender or extent of family responsibility. 
APPENDIX A: FIGURE 1 


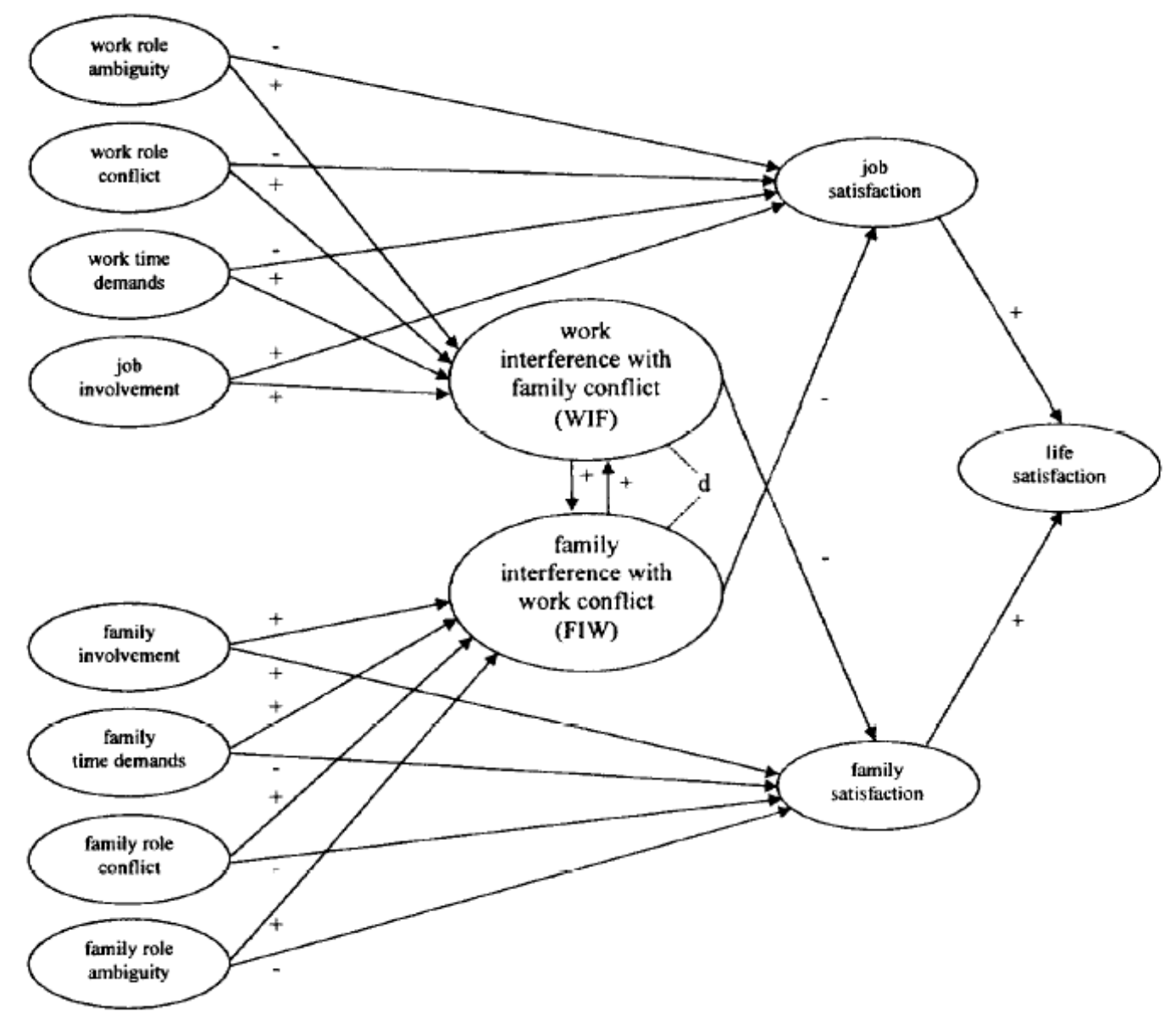

Carlson \& Kacmar (2000)

Figure 1 Work-family conflict model 
APPENDIX B: FIGURE 2 


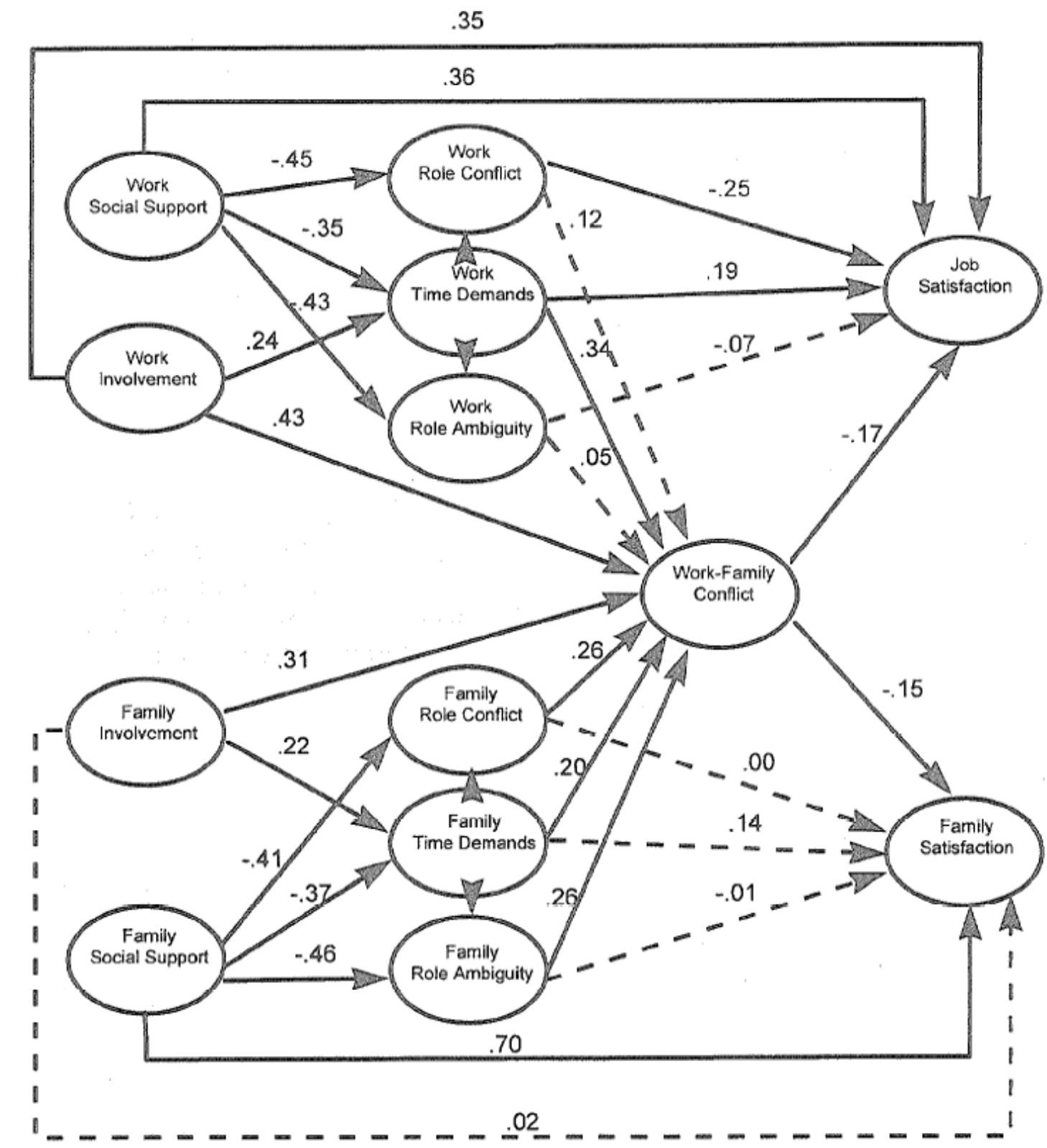

Carlson \& Perrewé (1999)

Figure 2 Work-family conflict model with social support as an antecedent to stressors 
APPENDIX C: INFORMED CONSENT LETTER (PART ONE) 


\section{Dear Research Participant,}

Thank you for volunteering to participate in the "Online Attitudes Questionnaire". You should be able to complete this study in 30 minutes or less. You will receive 1 point of ExperimenTrak credit for participating in this study. You must be 18 years of age or older to participate in this study.

Please review the questions in this survey and respond as indicated.

You will be asked to provide identifying information for this study, but your data will be kept confidential. Your data will be stored in a locked room, on password protected computers, and only the researcher team will have access to these data. The results of this study will only be reported at a group level; individual data will not be reported. As is the case with any research study sponsored by the University, you are free to withdraw from participation in this study without consequence. Further, you do not have to answer any questions that make you uncomfortable. If you wish to withdraw from the study, simply close the browser window.

If you have additional questions about your participation in this study, please contact myself or Dr. Fritzsche, using the information below. If you need to contact the UCF Student Counseling Center, their contact information is provided below as well.

Warm regards,

Kara C. Hickson

karahickson@cfl.rr.com

Barbara A. Fritzsche

bfritzsc@,mail.ucf.edu

(407) 823-5350

UCF Student Counseling Center

Student Resource Center, Room 203

(407) 823-2811

This research study has been reviewed and approved by the UCF Institutional Review Board. Questions or concerns about research participants' rights may be directed to the UCF IRB office, University of Central Florida, Office of Research \& Commercialization, 12201 Research Parkway, Suite 501, Orlando, FL 32826-3246. The telephone number is (407) 823-2901. I have read the procedure described above. By continuing with this survey and providing my name and date on the next page, I voluntarily agree to participate in the procedure and I have received a copy of this description. 
APPENDIX D: WORD SORT ONE 


\begin{tabular}{|l|l|}
\hline baseball & short stop \\
\hline car parts & brake \\
\hline baseball & catcher \\
\hline bank & guard \\
\hline tools & plane \\
\hline baseball & helmet \\
\hline baseball & dugout \\
\hline tools & vise \\
\hline car parts & gear \\
\hline bank & interest \\
\hline baseball & run \\
\hline tools & scissors \\
\hline bank & withdraw \\
\hline bank & alarm \\
\hline car parts & taillight \\
\hline baseball & first baseman \\
\hline car parts & seat \\
\hline baseball & catch \\
\hline baseball & minor league \\
\hline restaurant & hamburger \\
\hline baseball & curve \\
\hline car parts & hubcap \\
\hline baseball & foul \\
\hline bank & vault \\
\hline baseball & ball \\
\hline
\end{tabular}

\begin{tabular}{|l|l|}
\hline baseball & walk \\
\hline baseball & home plate \\
\hline car parts & turn signal \\
\hline baseball & slide \\
\hline car parts & rearview mirror \\
\hline baseball & foul line \\
\hline restaurant & tea \\
\hline baseball & field \\
\hline restaurant & drink \\
\hline restaurant & bill \\
\hline baseball & strike \\
\hline baseball & glove \\
\hline tools & knife \\
\hline car parts & dashboard \\
\hline restaurant & napkin \\
\hline baseball & scoreboard \\
\hline baseball & bat \\
\hline restaurant & spoon \\
\hline baseball & inning \\
\hline bank & deposit \\
\hline car parts & battery \\
\hline baseball & umpire \\
\hline restaurant & dressing \\
\hline restaurant & knife \\
\hline
\end{tabular}


APPENDIX E: WORD SORT TWO 


\begin{tabular}{|l|l|}
\hline bank & loan \\
\hline car parts & blinker \\
\hline bank & save \\
\hline bank & borrow \\
\hline restaurant & dessert \\
\hline restaurant & water \\
\hline bank & account \\
\hline baseball & coach \\
\hline car parts & accelerator \\
\hline car parts & trunk \\
\hline baseball & four ball \\
\hline tools & saw \\
\hline baseball & left fielder \\
\hline restaurant & breakfast \\
\hline car parts & bumper \\
\hline car parts & tire \\
\hline restaurant & menu \\
\hline baseball & fence \\
\hline bank & teller \\
\hline baseball & bunt \\
\hline car parts & headlight \\
\hline baseball & third baseman \\
\hline baseball & major league \\
\hline restaurant & dinner \\
\hline restaurant & fork \\
\hline bank & mortgage \\
\hline restaurant & lunch \\
\hline car parts & license plate \\
\hline restaurant & coffee \\
\hline bank & money \\
\hline restaurant & salt \\
\hline baseball & pitcher \\
\hline restaurant & check \\
\hline restaurant & order \\
\hline tools & drill \\
\hline baseball & second baseman \\
\hline baseball & steal \\
\hline bank & speedometer \\
\hline
\end{tabular}

\begin{tabular}{|l|l|}
\hline car parts & wheel \\
\hline baseball & cap \\
\hline car parts & horn \\
\hline baseball & hit \\
\hline tools & hammer \\
\hline tools & wrench \\
\hline car parts & windshield wiper \\
\hline tools & screwdriver \\
\hline baseball & right fielder \\
\hline tools & pliers \\
\hline bank & lend \\
\hline
\end{tabular}


APPENDIX F: PERFORMANCE EVALUATION RATING 


\begin{tabular}{|l|l|l|}
\hline Information about your teammate: & Man & Woman \\
\hline Was your teammate a man or a woman? & \multicolumn{2}{|l|}{} \\
\hline What was your teammate's major? & Yes & No \\
\hline I would work with my teammate in a future team-based study. & No \\
\hline $\begin{array}{l}\text { I would prefer to work with another teammate in a future team- } \\
\text { based study. }\end{array}$ & Yes & \\
\hline
\end{tabular}

\begin{tabular}{|c|c|c|c|c|c|}
\hline & $\begin{array}{l}\text { Strongly } \\
\text { Disagree }\end{array}$ & & & & $\begin{array}{c}\text { Strongly } \\
\text { Agree }\end{array}$ \\
\hline $\begin{array}{l}\text { 1. My teammate contributed his/her fair share to this } \\
\text { task. }\end{array}$ & 1 & 2 & 3 & 4 & 5 \\
\hline 2. My teammate was punctual. & 1 & 2 & 3 & 4 & 5 \\
\hline 3. My teammate was friendly. & 1 & 2 & 3 & 4 & 5 \\
\hline 4. My teammate was a hard worker. & 1 & 2 & 3 & 4 & 5 \\
\hline 5. My teammate was a quick learner. & 1 & 2 & 3 & 4 & 5 \\
\hline 6. My teammate did less work than me. (r) & 1 & 2 & 3 & 4 & 5 \\
\hline 7. My teammate angered me. (r) & 1 & 2 & 3 & 4 & 5 \\
\hline 8. My teammate responded quickly. & 1 & 2 & 3 & 4 & 5 \\
\hline 9. My teammate contributed more than me. & 1 & 2 & 3 & 4 & 5 \\
\hline 10. I liked working with my teammate. & 1 & 2 & 3 & 4 & 5 \\
\hline 11. My teammate was creative. & 1 & 2 & 3 & 4 & 5 \\
\hline $\begin{array}{l}\text { 12. My teammate's performance improved as we got } \\
\text { more involved in the task. }\end{array}$ & 1 & 2 & 3 & 4 & 5 \\
\hline 13. My teammate seemed intelligent. & 1 & 2 & 3 & 4 & 5 \\
\hline 14. I felt sorry for my teammate. & 1 & 2 & 3 & 4 & 5 \\
\hline 15. My teammate was responsible. & 1 & 2 & 3 & 4 & 5 \\
\hline
\end{tabular}

Items marked as (r) are reverse coded. 
APPENDIX G: TASK EVALUATION RATING 
We intend to conduct additional team-based studies of this nature in the future. Please answer the following questions about future studies:

\begin{tabular}{|c|c|c|c|c|c|}
\hline & $\begin{array}{l}\text { Strongly } \\
\text { Disagree }\end{array}$ & & & & $\begin{array}{c}\text { Strongly } \\
\text { Agree }\end{array}$ \\
\hline 1. I enjoyed this task. & 1 & 2 & 3 & 4 & 5 \\
\hline 2. I enjoy word-based tasks, in general. & 1 & 2 & 3 & 4 & 5 \\
\hline 3. The task was challenging. & 1 & 2 & 3 & 4 & 5 \\
\hline 4. The task was boring. (r) & 1 & 2 & 3 & 4 & 5 \\
\hline 5. The task required creativity. & 1 & 2 & 3 & 4 & 5 \\
\hline 6. I enjoy math-based tasks. & 1 & 2 & 3 & 4 & 5 \\
\hline 7. The task was fun. & 1 & 2 & 3 & 4 & 5 \\
\hline $\begin{array}{l}\text { 8. I would like to work on a task like this in future } \\
\text { studies. }\end{array}$ & 1 & 2 & 3 & 4 & 5 \\
\hline $\begin{array}{l}\text { 9. The } \$ 50 \text { reward was a good motivator for my } \\
\text { performance on this task. }\end{array}$ & 1 & 2 & 3 & 4 & 5 \\
\hline 10. The task was difficult. (r) & 1 & 2 & 3 & 4 & 5 \\
\hline 11. The task got easier as it progressed. & 1 & 2 & 3 & 4 & 5 \\
\hline 12. The task would have been easier face-to-face. (r) & 1 & 2 & 3 & 4 & 5 \\
\hline 13. I like Instant Messaging (IM), in general. & 1 & 2 & 3 & 4 & 5 \\
\hline 14. I use IM software often. & 1 & 2 & 3 & 4 & 5 \\
\hline $\begin{array}{l}\text { 15. I often use IM to work with classmates/colleagues to } \\
\text { complete school/work assignments. }\end{array}$ & 1 & 2 & 3 & 4 & 5 \\
\hline
\end{tabular}

Items marked as (r) are reverse coded. 
APPENDIX H: DEMOGRAPHIC SURVEY 


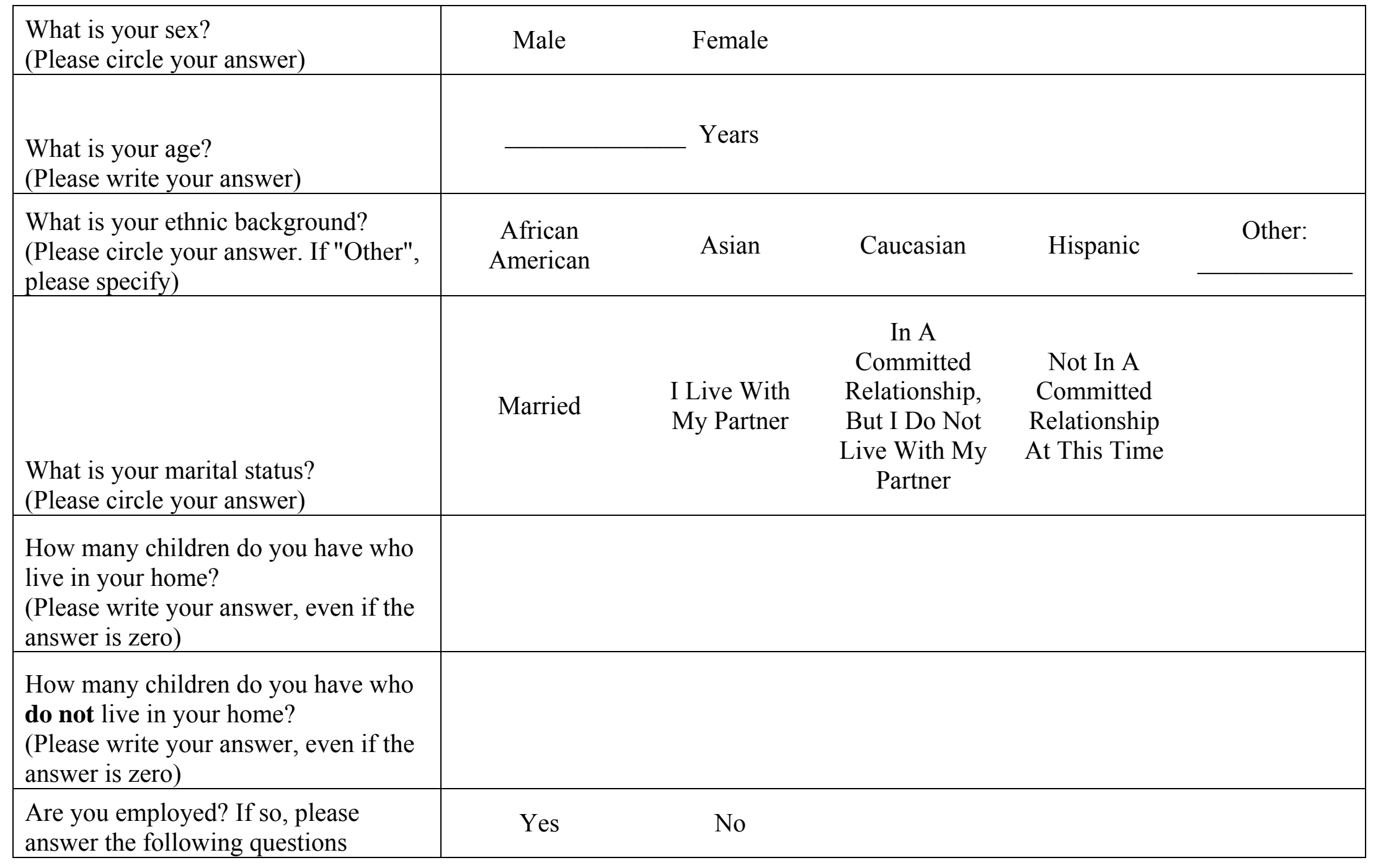




\begin{tabular}{|l|l|}
\hline $\begin{array}{l}\text { How many hours per week do you } \\
\text { work? }\end{array}$ & \\
\hline $\begin{array}{l}\text { What is your job title? } \\
\text { (Please write your answer) }\end{array}$ & \\
\hline $\begin{array}{l}\text { In what industry/occupation do you } \\
\text { work? } \\
\text { (Please write your answer) }\end{array}$ & Yes \\
\hline $\begin{array}{l}\text { Do you work in team-based settings in } \\
\text { your job? }\end{array}$ & Managerial No \\
\hline $\begin{array}{l}\text { Is your job role managerial or non- } \\
\text { managerial? }\end{array}$ & $\begin{array}{c}\text { Non- } \\
\text { Managerial }\end{array}$ \\
\hline
\end{tabular}


APPENDIX I: WORK-FAMILY CONFLICT MEASURE 


\begin{tabular}{|c|c|c|c|c|c|}
\hline & $\begin{array}{l}\text { Strongly } \\
\text { Disagree }\end{array}$ & & & & $\begin{array}{l}\text { Strongly } \\
\text { Agree }\end{array}$ \\
\hline $\begin{array}{l}\text { 1. My work keeps me from my family activities } \\
\text { more than I would like. }\end{array}$ & 1 & 2 & 3 & 4 & 5 \\
\hline $\begin{array}{l}\text { 2. The time I must devote to my job keeps me from } \\
\text { participating equally in household activities and } \\
\text { responsibilities. }\end{array}$ & 1 & 2 & 3 & 4 & 5 \\
\hline $\begin{array}{l}\text { 3. I have to miss family activities due to the amount } \\
\text { of time I must spend on work responsibilities. }\end{array}$ & 1 & 2 & 3 & 4 & 5 \\
\hline $\begin{array}{l}\text { 4. The time I spend on family responsibilities often } \\
\text { interfere with my work responsibilities. }\end{array}$ & 1 & 2 & 3 & 4 & 5 \\
\hline $\begin{array}{l}\text { 5. The time I spend with my family often causes me } \\
\text { not to spend time in activities at work that could be } \\
\text { helpful to my career. }\end{array}$ & 1 & 2 & 3 & 4 & 5 \\
\hline $\begin{array}{l}\text { 6. I have to miss work activities due to the amount } \\
\text { of time I must spend on family responsibilities. }\end{array}$ & 1 & 2 & 3 & 4 & 5 \\
\hline $\begin{array}{l}\text { 7. When I get home from work I am often to } \\
\text { frazzled to participate in family } \\
\text { activities/responsibilities. }\end{array}$ & 1 & 2 & 3 & 4 & 5 \\
\hline $\begin{array}{l}\text { 8. I am often so emotionally drained when I get } \\
\text { home from work that it prevents me from } \\
\text { contributing to my family. }\end{array}$ & 1 & 2 & 3 & 4 & 5 \\
\hline $\begin{array}{l}\text { 9. Due to all the pressures at work, sometimes when } \\
\text { I come home I am too stressed to do the things I } \\
\text { enjoy. }\end{array}$ & 1 & 2 & 3 & 4 & 5 \\
\hline $\begin{array}{l}\text { 10. Due to stress at home, I am often preoccupied } \\
\text { with family matters at work. }\end{array}$ & 1 & 2 & 3 & 4 & 5 \\
\hline $\begin{array}{l}\text { 11. Because I am often stressed from family } \\
\text { responsibilities, I have a hard time concentrating on } \\
\text { my work. }\end{array}$ & 1 & 2 & 3 & 4 & 5 \\
\hline $\begin{array}{l}\text { 12. Tension and anxiety from my family life often } \\
\text { weakens my ability to do my job. }\end{array}$ & 1 & 2 & 3 & 4 & 5 \\
\hline $\begin{array}{l}\text { 13. The problem-solving behaviors I use in my job } \\
\text { are not effective in resolving problems at home. }\end{array}$ & 1 & 2 & 3 & 4 & 5 \\
\hline
\end{tabular}




\begin{tabular}{|c|c|c|c|c|c|}
\hline $\begin{array}{l}\text { 14. Behavior that is effective and necessary for me } \\
\text { at work would be counterproductive at home. }\end{array}$ & 1 & 2 & 3 & 4 & 5 \\
\hline $\begin{array}{l}\text { 15. The behaviors I perform that make me effective } \\
\text { at work do not help me to be a better parent and } \\
\text { partner at home. }\end{array}$ & 1 & 2 & 3 & 4 & 5 \\
\hline $\begin{array}{l}\text { 16. The behaviors that work for me at home do not } \\
\text { seem to be effective at work. }\end{array}$ & 1 & 2 & 3 & 4 & 5 \\
\hline $\begin{array}{l}\text { 17. Behavior that is effective and necessary for me } \\
\text { at home would be counterproductive at work. }\end{array}$ & 1 & 2 & 3 & 4 & 5 \\
\hline $\begin{array}{l}\text { 18. The problem-solving behaviors that work for me } \\
\text { at home do not seem to be as useful at work. }\end{array}$ & 1 & 2 & 3 & 4 & 5 \\
\hline
\end{tabular}


APPENDIX J: ATTITUDES TOWARD TEAMWORK SURVEY 


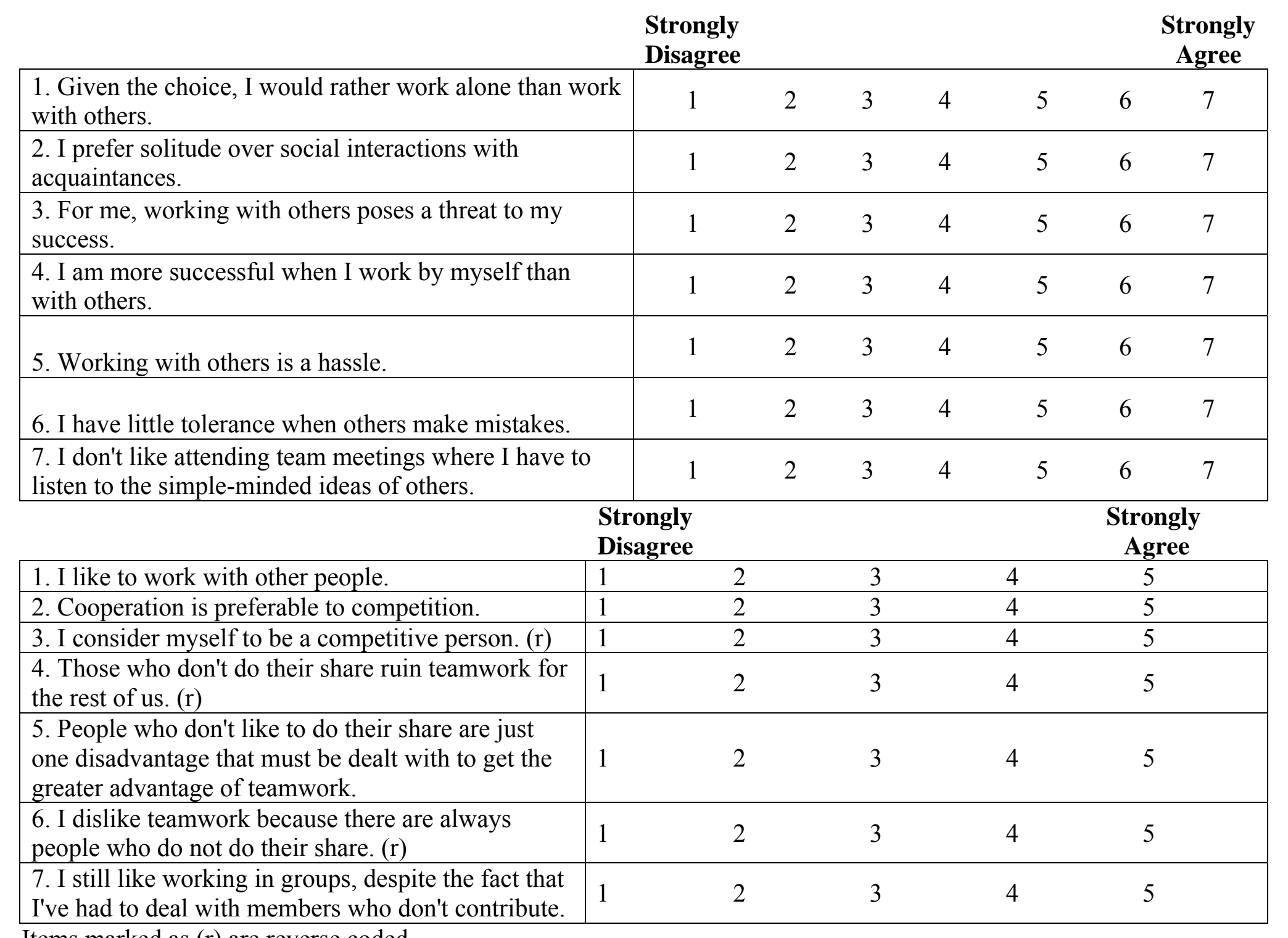

Items marked as (r) are reverse coded. 
APPENDIX K: AGREEABLENESS MEASURE 
Instructions: On the following pages, there are phrases describing people's behaviors. Please use the rating scale below to describe how accurately each statement describes you. Describe yourself as you generally are now, not as you wish to be in the future. Describe yourself as you honestly see yourself, in relation to other people you know of the same sex as you are, and roughly your same age. So that you can describe yourself in an honest manner, your responses will be kept in absolute confidence. Please read each statement carefully, and then fill in the bubble that corresponds to the number on the scale.

\section{Response Options}

1: Very Inaccurate

2: Moderately Inaccurate

3: Neither Inaccurate nor Accurate

4: Moderately Accurate

5: Very Accurate

\begin{tabular}{|l|l|}
\hline 1 & Love children. \\
\hline 2 & Show my gratitude. \\
\hline 3 & Love to help others. \\
\hline 4 & Take time out for others. \\
\hline 5 & Have a good word for everyone. \\
\hline 6 & Am hard to get to know. (r) \\
\hline 7 & Am not really interested in others. (r) \\
\hline 8 & Am interested in people. \\
\hline 9 & Know how to comfort others. \\
\hline 10 & Am indifferent to the feelings of others. (r) \\
\hline 11 & Sympathize with others' feelings. \\
\hline 12 & Feel little concern for others. (r) \\
\hline 13 & Inquire about others' well-being. \\
\hline 14 & Make people feel at ease. \\
\hline 15 & Insult people. (r) \\
\hline 16 & Am on good terms with nearly everyone. \\
\hline 17 & Have a soft heart. \\
\hline 18 & Am not interested in other people's problems. (r) \\
\hline 19 & Think of others first. \\
\hline 20 & Feel others' emotions. \\
\hline
\end{tabular}

Items marked as (r) are reverse coded. 
APPENDIX L: PROSOCIAL PERSONALITY BATTERY 


\begin{tabular}{|c|c|}
\hline 1 & $\begin{array}{l}\text { If a good friend of mine wanted to injure an enemy of theirs, it would be my duty } \\
\text { to try to stop them. }\end{array}$ \\
\hline 2 & $\begin{array}{l}\text { I wouldn't feel that I had to do my part in a group project if everyone else was } \\
\text { lazy. (r) }\end{array}$ \\
\hline 3 & When people are nasty to me, I feel very little responsibility to treat them well. \\
\hline 4 & I would feel less bothered about leaving litter in a dirty park than in a clean one. (r) \\
\hline 5 & $\begin{array}{l}\text { No matter what a person has done to us, there is no excuse for taking advantage of } \\
\text { them. }\end{array}$ \\
\hline 6 & $\begin{array}{l}\text { You can't blame basically good people who are forced by their environment to be } \\
\text { inconsiderate of others. (r) }\end{array}$ \\
\hline 7 & $\begin{array}{l}\text { No matter how much people are provoked, they are always responsible for } \\
\text { whatever they do. }\end{array}$ \\
\hline 8 & $\begin{array}{l}\text { Being upset or preoccupied does not excuse people for doing anything they would } \\
\text { ordinarily avoid. }\end{array}$ \\
\hline 9 & $\begin{array}{l}\text { As long as people do not break laws, they should feel free to do their business as } \\
\text { they see fit. (r) }\end{array}$ \\
\hline 10 & $\begin{array}{l}\text { Occasionally in life, people find themselves in a situation in which they have } \\
\text { absolutely no control over what they do to others. (r) }\end{array}$ \\
\hline 11 & $\begin{array}{l}\text { I would feel obligated to do a favor for someone who needed it, even though they } \\
\text { had shown no gratitude for past favors. }\end{array}$ \\
\hline 12 & $\begin{array}{l}\text { With the pressure for grades and the widespread cheating in school nowadays, the } \\
\text { individual who cheats occasionally is not really as much at fault. }(\mathrm{r})\end{array}$ \\
\hline 13 & $\begin{array}{l}\text { It doesn't make much sense to be very concerned about how we act when we are } \\
\text { sick and feeling miserable. (r) }\end{array}$ \\
\hline 14 & $\begin{array}{l}\text { If I broke a machine through mishandling, I would feel less guilty if it was already } \\
\text { damaged before I used it. (r) }\end{array}$ \\
\hline 15 & $\begin{array}{l}\text { When you have a job to do, it is impossible to look out for everybody's best } \\
\text { interest. (r) }\end{array}$ \\
\hline 16 & I often have tender, concerned feelings for people less fortunate than me. \\
\hline 17 & $\begin{array}{l}\text { I sometimes find it difficult to see things from the "other person's" point of view. } \\
\text { (r) }\end{array}$ \\
\hline 18 & $\begin{array}{l}\text { Sometimes I don't feel very sorry for other people when they are having problems. } \\
\text { (r) }\end{array}$ \\
\hline 19 & In emergency situations, I feel apprehensive and ill-at-ease. \\
\hline 20 & I try to look at everybody's side of a disagreement before I make a decision. \\
\hline 21 & $\begin{array}{l}\text { When I see someone being taken advantage of, I feel kind of protective towards } \\
\text { them. }\end{array}$ \\
\hline 22 & $\begin{array}{l}\text { I sometimes try to understand my friends better by imagining how things look } \\
\text { from their perspective. }\end{array}$ \\
\hline 23 & Other people's misfortunes do not usually disturb me a great deal. (r) \\
\hline
\end{tabular}




\begin{tabular}{|c|c|}
\hline 24 & $\begin{array}{l}\text { If I'm sure I'm right about something, I don't waste much time listening to other } \\
\text { people's arguments. (r) }\end{array}$ \\
\hline 25 & Being in a tense emotional situation scares me. \\
\hline 26 & $\begin{array}{l}\text { When I see someone being treated unfairly, I sometimes don't feel very much pity } \\
\text { for them. (r) }\end{array}$ \\
\hline 27 & I am usually pretty effective in dealing with emergencies. (r) \\
\hline 28 & I am often quite touched by things that I see happen. \\
\hline 29 & I believe that there are two sides to every question and try to look at them both. \\
\hline 30 & I would describe myself as a pretty soft-hearted person. \\
\hline 31 & I tend to lose control during emergencies. \\
\hline 32 & When I'm upset at someone, I usually try to "put myself in their shoes" for a while. \\
\hline 33 & When I see someone who badly needs help in an emergency, I go to pieces. \\
\hline 34 & $\begin{array}{l}\text { Before criticizing somebody, I try to imagine how I would feel if I were in their } \\
\text { place. }\end{array}$ \\
\hline 35 & My decisions are usually based on my concern for other people. \\
\hline 36 & My decisions are usually based on what is the most fair and just way to act. \\
\hline 37 & I choose alternatives that are intended to meet everybody's needs. \\
\hline 38 & I choose a course of action that maximizes the help other people receive. \\
\hline 39 & I choose a course of action that considers the rights of all people involved. \\
\hline 40 & My decisions are usually based on concern for the welfare of others. \\
\hline 41 & $\begin{array}{l}\text { My decisions are usually based on my personal principles about what is fair and } \\
\text { unfair. }\end{array}$ \\
\hline 42 & I choose alternatives that minimize the negative consequences to other people. \\
\hline 43 & I have given directions to a stranger. \\
\hline 44 & I have made change for a stranger. \\
\hline 45 & I have given money to a stranger who needed it (or asked me for it). \\
\hline 46 & I have donated goods or clothes to a charity. \\
\hline 47 & I have done volunteer work for a charity. \\
\hline 48 & I have helped carry a stranger's belongings (e.g., books, parcels, etc.). \\
\hline 49 & I have delayed an elevator and held the door open for a stranger. \\
\hline 50 & $\begin{array}{l}\text { I have allowed someone to go ahead of me in a line (e.g., supermarket, copying } \\
\text { machine, etc.). }\end{array}$ \\
\hline 51 & I have given a stranger a lift in my car. \\
\hline 52 & $\begin{array}{l}\text { I have let a neighbor whom I didn't know too well borrow an item of some value } \\
\text { (e.g., tools, a dish, etc.). }\end{array}$ \\
\hline 53 & $\begin{array}{l}\text { I have bought "charity" Christmas cards deliberately because I knew it was for a } \\
\text { good cause. }\end{array}$ \\
\hline 54 & $\begin{array}{l}\text { I have helped a classmate who I did not know that well with a homework } \\
\text { assignment when my knowledge was greater than his or hers. }\end{array}$ \\
\hline 55 & $\begin{array}{l}\text { I have, before being asked, voluntarily looked after a neighbor's pets or children } \\
\text { without being paid for it. }\end{array}$ \\
\hline 56 & I have offered to help a handicapped or elderly stranger across a street. \\
\hline
\end{tabular}

Items marked as (r) are reverse coded. 
APPENDIX M: BEM SEX ROLE INVENTORY 
Instructions: Rate yourself on each item, on a scale from 1 (never or almost never true) to 7 (almost always true).

\begin{tabular}{|l|l|}
\hline 1. self reliant & 31. makes decisions easily \\
\hline 2. yielding & 32. compassionate \\
\hline 3. helpful & 33. sincere \\
\hline 4. defends own beliefs & 34. self-sufficient \\
\hline 5. cheerful & 35. eager to soothe hurt feelings \\
\hline 6. moody & 36. conceited \\
\hline 7. independent & 37. dominant \\
\hline 8. shy & 38. soft spoken \\
\hline 9. conscientious & 39. likable \\
\hline 10. athletic & 40. masculine \\
\hline 11. affectionate & 41. warm \\
\hline 12. theatrical & 42. solemn \\
\hline 13. assertive & 43. willing to take a stand \\
\hline 14. flatterable & 44. tender \\
\hline 15. happy & 45. friendly \\
\hline 16. strong personality & 46. aggressive \\
\hline 17. loyal & 47. gullible \\
\hline 18. unpredictable & 48. inefficient \\
\hline 19. forceful & 49. acts as a leader \\
\hline 20. feminine & 50. childlike \\
\hline 21. reliable & 51. adaptable \\
\hline 22. analytical & 52. individualistic \\
\hline 23. sympathetic & 53. does not use harsh language \\
\hline 24. jealous & 54. unsystematic \\
\hline 25. leadership ability & 55. competitive \\
\hline 26. sensitive to other's needs & 56. loves children \\
\hline 27. truthful & 57. tactful \\
\hline 28. willing to take risks & 58. ambitious \\
\hline 29. understanding & 59. gentle \\
\hline 30. secretive & 60. conventional \\
\hline & \\
\hline
\end{tabular}


APPENDIX N: INFORMED CONSENT LETTER (PART TWO) 
Thank you for volunteering to participate in the "An assessment of the use of instant messaging (IM) software to complete two-person tasks" study. An hour has been allotted for administration of this study, to ensure you have sufficient time to complete all tasks. You will receive 2 points of Research Experience credit for participating in this study. You must be 18 years of age or older to participate.

The purpose of this experiment is to assess the use of instant messaging (IM) software in completing a two-person task. You will use IM software to complete a series of twenty questions games with your teammate. The variant of the game will be "Animal, Vegetable/Fruit, Transportation." You and your teammate will each have a list of 25 words and will alternate turns as questioner or responder.

At the start of the each round, the responder will tell the questioner to which category the word belongs. The goal of the game is for the questioner to determine the word, using as few yes/no questions as possible. For example, suppose the word is elephant. The answerer would start by saying, "Animal." The questioner could ask questions such as, "Is this animal a pet?" The question/response activity will continue until the object has been identified, or until 20 questions have been asked.

The researcher will monitor the session and record the number of questions asked by the questioner. When 20 questions have been asked and the word has not yet been identified, the team will be instructed to proceed to the next word on the list, and change roles (former questioner becomes responder).

The goal of the game is to identify as many words on the list as possible. The top three scoring teams in this study will receive a $\$ 50$ gift card for each teammate. In the event that all 50 words are identified in the 20 minute time period for more than three groups, the prizes will be awarded to the participants with the fastest completion time.

In addition to the team task, you will also complete an individual word-sort task. You will sort 50 index cards with words printed on them into categories, then try to recall as many of these fifty words as possible.

You will be asked to provide identifying information for this study, but your data will be kept confidential. Your data will be stored in a locked room, on password protected computers, and only the research team will have access to these data. The results of this study will only be reported at a group level; individual data will not be reported. As is the case with any research study sponsored by the University, you are free to withdraw from participation in this study without consequence. Further, you do not have to answer any questions that make you uncomfortable. If you wish to withdraw from the study, simply hand your materials to the researcher and tell him/her that you are no longer interested in participating. 
To prevent distractions, the researcher will place your belongings in a safe place for the duration of the study.

If you have additional questions about your participation in this study, please contact Kara Hickson or Dr. Fritzsche, using the provided information. If you need to contact the UCF Student Counseling Center, their contact information is provided as well.

"An assessment of the use of instant messaging (IM) software to complete two-person tasks"

Researcher Contact Information

Kara C. Hickson

karachickson@gmail.com

Barbara A. Fritzsche

bfritzsc@mail.ucf.edu

(407) 823-5350

UCF Student Counseling Center

Student Resource Center, Room 203

(407) 823-2811

This research study has been reviewed and approved by the UCF Institutional Review Board. Questions or concerns about research participants' rights may be directed to the UCF IRB office, University of Central Florida, Office of Research \& Commercialization, 12201 Research Parkway, Suite 501, Orlando, FL 32826-3246. The telephone number is (407) 823-2901. 
APPENDIX O: EXPERIMENTER SCRIPT 
- Experimenter One comes to get you (Experimenter Two).

- Go into participant room.

- INSERT CONDITION HERE (This is Condition A) Say to Participant (use post it note prompt), "Your teammate, Jennifer, just called and she'll be here in 10 minutes. She's running late because she had a doctor's appointment that she forgot about. We will start the team part as soon as she gets here"

o Experimenter One says to You, "Do you think it would be okay for her/him (participant) to do Jennifer's sort?"

o Say to Participant, "That would work, because it is a different set of words and it won't effect the team score. Otherwise, Jennifer will have to stay after to do it. But it is up to you...it doesn't make a difference to us."

- Go back to Lab, bring cards to participant if they agree to help.

- After Participant One types "we are ready"

- USE CONDITION INFORMATION HERE (This is Condition A)

TYPE “Hi I am Jennifer. Sorry I am late. I forgot I had a doctor's appointment. I am a psych major, and I like to spend time with my husband and 2 year old daughter.

- TYPE "My experimenter said I will be the first questioner, and that you would provide the first category"

- After Participant One types category, proceed with game.

o First type the questions on the twenty questions script

o Then answer the questions about the words the participant is trying to solve. 
o Condition A: "Your teammate, Jennifer, just called and she'll be here in 10 minutes. She's running late because she had a doctor's appointment that she forgot about. We will start the team part as soon as she gets here"

o Condition B: "Your teammate, Jennifer, just called and she'll be here in 10 minutes. She's running late because she forgot she had to take her daughter to a doctor's appointment. We will start the team part as soon as she gets here."

o Condition C: "Your teammate, Jennifer, just called and she'll be here in 10 minutes. She's running late because she got sick and had to go to the doctor earlier. We will start the team part as soon as she gets here."

o Condition D: "Your teammate, Jennifer, just called and she'll be here in 10 minutes. She's running late because her daughter got sick and she had to take her to the doctor earlier. We will start the team part as soon as she gets here."

o Condition E: "Your teammate, Matthew, just called and he'll be here in 10 minutes. He's running late because he had a doctor's appointment that he forgot about. We will start the team part as soon as he gets here."

o Condition F: "Your teammate, Matthew, just called and he'll be here in 10 minutes. He's running late because he forgot he had to take his daughter to a doctor's appointment. We will start the team part as soon as he gets here."

o Condition G: "Your teammate, Matthew, just called and he'll be here in 10 minutes. He's running late because he got sick and had to go to the doctor earlier. We will start the team part as soon as he gets here."

o Condition H: "Your teammate, Matthew, just called and he'll be here in 10 minutes. He's running late because his daughter got sick and he had to take her to the doctor earlier. We will start the team part as soon as he gets here." 
APPENDIX P: PARTICIPANT 20 QUESTIONS 


\begin{tabular}{|l|l|}
\hline Word & Category \\
\hline 1. ship & transportation \\
\hline 2. alligator & animal \\
\hline 3. bird & animal \\
\hline 4. dog & animal \\
\hline 5. rabbit & animal \\
\hline 6. motorcycle & transportation \\
\hline 7. ant & animal \\
\hline 8. lime & fruit/veg \\
\hline 9. onion & fruit/veg \\
\hline 10. tiger & animal \\
\hline 11. airplane & transportation \\
\hline 12. train & transportation \\
\hline 13. peas & fruit/veg \\
\hline 14. cucumber & fruit/veg \\
\hline 15. eggplant & fruit/veg \\
\hline 16. deer & animal \\
\hline 17. grapefruit & fruit/veg \\
\hline 18. rat & animal \\
\hline 19. cabbage & fruit/veg \\
\hline 20. boat & transportation \\
\hline 21. taxi & transportation \\
\hline 22. bus & transportation \\
\hline 23. owl & animal \\
\hline 24. carrot & fruit/veg \\
\hline 25. apple & fruit/veg \\
\hline & \\
\hline
\end{tabular}


APPENDIX Q: CONFEDERATE 20 QUESTIONS 
1. corn (fruit/veg)
a. Is it a fruit?
b. Is it round?
c. Is it orange?
d. Is it green?
e. Is it yellow?
f. Do you find it in a normal salad?
g. Is it corn?

2. eagle (animal)
a. Does it walk on four legs?
b. Does it swim?
c. Does it fly?
d. Is it a bat?
e. Is it a flying squirrel?
f. Is it a type of bird?
g. Is it white?
h. Is it endangered?
i. Is it an eagle?

3. bicycle (transportation)
a. Four wheels?
b. Does it have two?
c. Does it have an engine?
d. A bicycle

4. helicopter (transportation)
a. Does it fly?
b. Is it big?
c. Is it an airplane?
d. Is it a helicopter?

5. zebra (animal)
a. Is it small?
b. Does it have legs?
c. 4 legs?
d. Is it bigger than a cat?
e. Is it native to the US?
f. Is it from Africa?
g. Does it have fur?
h. Is it brown?
i. Is it black?
j. Zebra?

6. potato (fruit/veg)
a. Is it a fruit?
b. Is it green?
c. Is it a dessert?
d. Do we eat hot?
e. Is it round?
f. Is it oval?
g. Does it grow underground?
h. Is it a carrot?
i. Is it a potato?

7. subway (transportation)
a. Does it have a motor?
b. Does it have wheels? (if no, skip next two questions)
c. Is it 2 wheels?
d. Does it have four wheels?
e. Is it a semi-truck?
f. Does it fly?
g. Is it an automobile?
h. Is it public transportation?
i. Is it a train?
j. Is it a subway?

8. goldfish (animal)
a. Does it swim?
b. Is it in the fish family?
c. Is it bigger than a salmon?
d. Is it a shrimp?
e. Is it found in freshwater?
f. Is it a tilapia?
g. Is it a common food?
h. Is it a pet?
i. goldfish

9. orange (fruit/veg)
a. Is it a fruit?
b. Does it grow on a tree?
c. Is it orange?
d. It's an orange 
10. crocodile (animal)
a. Is it a mammal?
b. Does it fly?
c. Does it swim?
d. Is it in the fish family?
e. Is it a reptile?
f. Is it a carnivore?
g. Is it a common food?
$\mathrm{h}$. Is it a reptile?
i. Alligator?
j. Crocodile?

11. celery (fruit/veg)
a. Is it a fruit?
b. Does it grow underground?
c. Can it be found at subway?
d. Is it green?
e. Is it a bean?
f. Is it served hot?
g. Is it a squash?
h. Is it a common food?
i. Brussels sprouts?
j. Is it two words?
k. Broccoli?
1. Celery?

12. cow (animal)
a. Is it a mammal?
b. Does it walk on 4 legs?
c. Does it have fur?
d. Is it a common pet?
e. Does it have a tail?
f. Is it normally found in the US?
g. Is it smaller than a dog?
h. Do people normally ride them?
i. Is it brown?
$\mathrm{j}$. Is it a common food?
$\mathrm{k}$. Is it a cow?

13. turtle (animal)
a. Is it a mammal?
b. Does it fly?
c. Does it swim?
d. Is it a reptile?
e. Does it live in the water?
f. Is it green?
g. Is it a snake?
h. Is it a lizard?
i. Does it have a shell?
j. Turtle

14. Rat (animal)
a. Is it a mammal?
b. Does it fly?
c. Can it be found in the zoo?
d. Can it be found on a farm?
e. Does it have four legs?
f. Can you ride it?
g. Is it a dog?
h. Is it bigger than an adult person?
i. Does it live in the ground?
j. Does it live in a tree?
k. Raccoon?
1. Is it a cat?
m. Does it have fur?
n. Is it brown?
o. Can u find them around ucf?
p. Squirrel?
q. Is it a rat?

15. lettuce (fruit/veg)
a. Is it a fruit?
b. Is it green?
c. Does it grow underground?
d. Is it normally on a salad?
e. Is it a pepper?
f. Is it lettuce? 
16. truck (transportation)
a. Does it have a motor?
b. Does it have wheels?
c. Does it fly?
d. Is it public transportation?
e. Is it used in florida?
f. Does it have 4 wheels?
g. Is it a car?
h. Is it a truck?

17. banana (fruit/veg)
a. Is it a vegetable?
b. Is it red?
c. Is it orange?
d. Is it yellow?
e. Is it a lemon?
f. Is it a banana?

18. airplane (transportation)
a. Does it travel on roads?
b. Does it have one or more wheels?
c. Does it fly?
d. Is it an airplane?

19. Kiwi (fruit/veg)
a. Is it a fruit?
b. Does it have seeds?
c. Does it come in different colors?
d. Is it green?
e. Is it soft?
f. Is the skin hard?
g. Is it a tropical fruit?
h. Is it fuzzy?
i. Is it a kiwi?

20. Strawberry (fruit/veg)
a. Is it a fruit?
b. Does it have tough skin?
c. Is it usually green?
d. Is it orange?
e. Is it red when ripe?
f. Does it have lots of seeds?
g. Is it used in desserts?

h. Is it a cherry?

i. Strawberry?

21. spider (animal)
a. Is it small?
b. Is it an insect?
c. Would it be an arachnid?
d. Spider?

22. Tangerine (fruit/veg)
a. Is it a fruit?
b. Is it round?
c. Is it red?
d. Is it yellow?
e. Is it orange?
f. Is it an orange?
g. Is it a peach?
h. Is it a mango?
i. Ohhhh...is it a tangerine?

23. bee (animal)
a. Is it a mammal?
b. Reptile?
c. Does it swim?
d. Does it fly?
e. Is it a bird?
f. Is it an insect?
g. Can it sting?
h. Is it a bee?

24. car (transportation)
a. Does it have a motor?
b. Does it fly?
c. Does it drive on the road?
d. Do most people own one?

25. horse (animal)
a. Does it have paws?
b. Does it stand on two legs?
c. Is it brown?
d. Would you find it on the farm?
e. Can you see it in a zoo?
f. Does it win races?
g. Is it a horse? 
APPENDIX R: DEBRIEFING QUESTIONNAIRE 
Debriefing Form (read to participant and record answers to questions)

Thank you for participating in the "An assessment of the use of instant messaging (IM) software to complete two-person tasks" study.

Do you know what the purpose of this study is?

The purpose of the study you participated in today was to examine the relationship between parental gender, reason for tardiness, control over tardiness, and actions toward teammates. To measure these relationships, we created a controlled environment in which these variables were manipulated. The person who acted as your teammate was a partner of the researcher.

Did you think that your partner was a real teammate, or did you have concerns that this was part of the manipulation? If, so what specifically made you think this?

Was your teammate a man or a woman?

1. Man

2. Woman

Your teammate late because:

1. They were sick and had to go to the Doctor

2. They forgot they had a Doctors appointment

Who had to go to the Doctor?

1. Your teammate

2. Your teammate's child 
APPENDIX S: DEBRIEFING LETTER 
You were assigned to one of eight experimental conditions, in which sex of your teammate, reason for tardiness (self-related versus child related), and control over the reason for tardiness (forgotten medical checkup versus emergency medical need) were manipulated.

Thus, if you were in the condition with a female teammate who was late because she unexpectedly had to take her sick daughter to the doctor, the experimenter provided you with the following information, "Your teammate, Jennifer, just called and she'll be here in 10 minutes. She's running late because her daughter got sick and she had to take her to the doctor earlier."

Earlier this semester, you also participated in the "Online Attitudes Questionnaire". The data collected from that study and the one you participated in today were part of a larger data collection effort for Kara Hickson's doctoral dissertation. The data you provided in the "Online Attitudes Questionnaire" was used to explore the relationship of your reported work and family responsibilities, personality, sex-role beliefs, and attitudes toward teamwork with your evaluations about and helping behaviors toward your teammate. Today, we did not assess this information during this experimental session because we did not want your responses to these measures to impact your behaviors in the team task.

Mild deception is often used in social psychological research in order to create experimental realism. It is difficult to think of a way to study how people will respond to a teammate who is tardy without putting them in the situation, as self-reports of this behavior are likely to be influenced by what is socially acceptable to say. Given the nature of this study, we ask you not to share your experience in this research project with other students. The success of our research efforts is dependent on our ability to create experimental realism, and if participants are aware of the association between parts one and parts two, or the use of a partner of the researcher as a teammate in part two, the results will not be authentic. Your cooperation is greatly appreciated.

As stated in the study instructions, the goal of the twenty questions game was to identify as many words on the list as possible. The top three scorers in this study will receive a $\$ 50$ Visa gift card from a banking institution, so that the gift card can be used wherever Visa is accepted. The reward is performance-based.

For example, if the greatest number of words identified is 15 , and the second and third greatest number of words identified are 13 and 11, respectively, these folks will earn the gift cards. In the unlikely event that all 50 words are identified by one or more participants, the prizes will be awarded first to the participants who identified all fifty words in ascending order of completion time, then to participants with the greatest number of words identified, until all three gift cards are distributed.

As stated earlier, your teammate was a partner of the researcher. To ensure fairness for participants who were competing for the $\$ 50$ gift cards, we scripted your teammate's 
responses in the team activity. When the teammate was the questioner, he/she always asked the same number of questions to arrive at the correct answer, so performance was held constant across conditions. Thus, teammate interaction was not expected to influence your performance, as teammate questions are scripted and teammate responses are participant driven (i.e., based on your questions).

This study will help us to better explain the relationship between family responsibilities and work-family conflict (WFC), a type of interrole conflict in which role pressures from the work and family domains are mutually incompatible to some degree (Kahn, Wolfe, Quinn, Snoek, \& Rosenthal, 1964; Greenhaus \& Beutell, 1985). The results of this study may provide further support for family friendly workplace policies such as flexible work schedules and accommodating family medical leave policies. Additionally, these findings may help organizations to further reduce unjust bias against employed parents in performance evaluation systems.

We greatly appreciate your participation in this study. If you have additional questions about your participation in this study, would like to withdraw the data you provided from this study, or would like to obtain the results of the study after it has been completed, please contact Kara Hickson or Dr. Fritzsche, using the information provided on the Contact Sheet. If you feel that you have been harmed in any way by participating in this study, please contact Kara, Dr. Fritzsche, or the UCF Student Counseling Center. Thank you, again, for your participation! And, please let the experimenter know if you have additional questions. 
APPENDIX T: TABLE 1 
Table 1

Descriptive Statistics, Internal Consistency Estimates, and Intercorrelations for Individual Differences Measures and Evaluation and Task Ratings

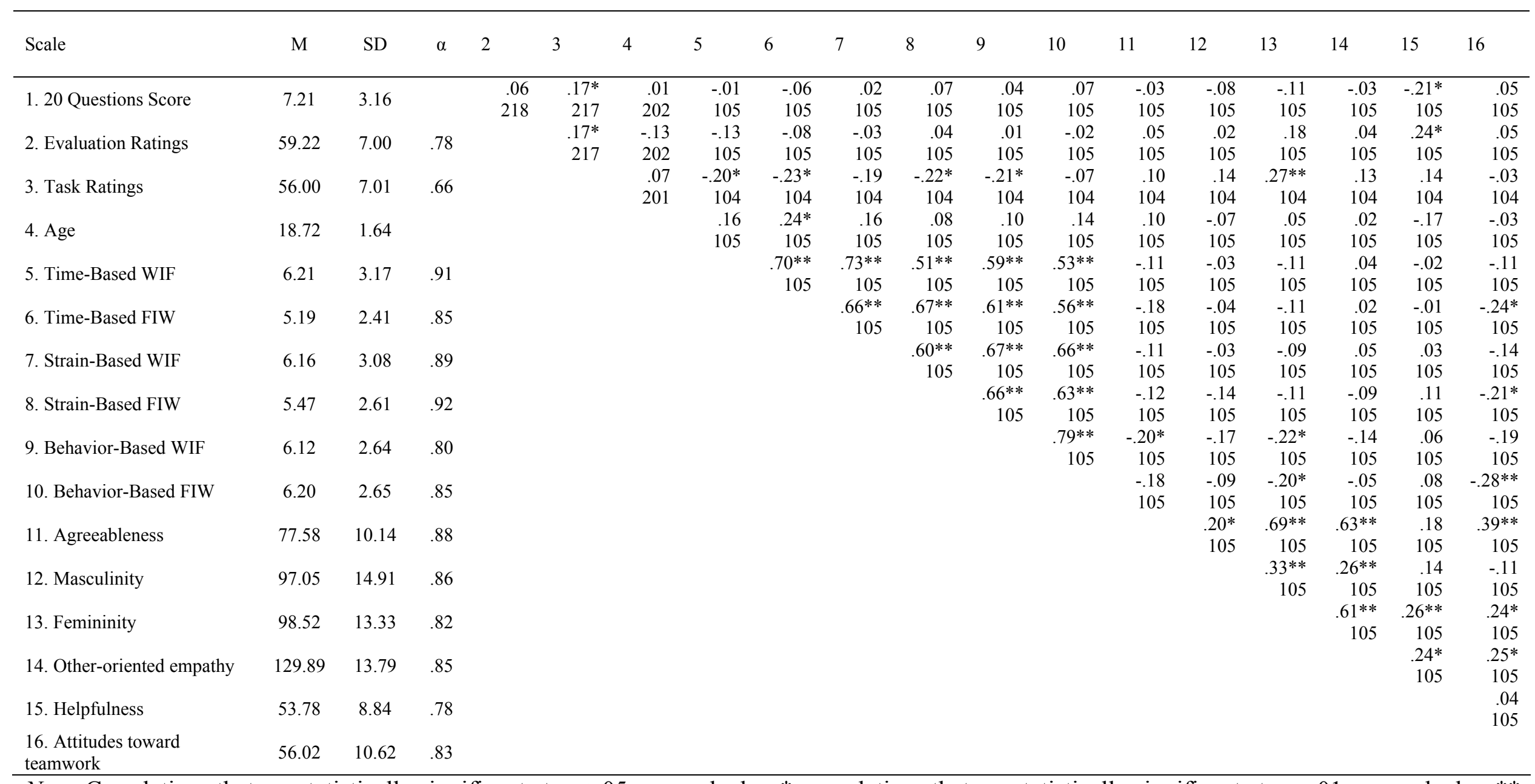

Note. Correlations that are statistically significant at $p<.05$ are marked as *; correlations that are statistically significant at $p<.01$ are marked as $* *$.

Sample sizes are reported below each correlation coefficient. 
APPENDIX U: FIGURE 3 

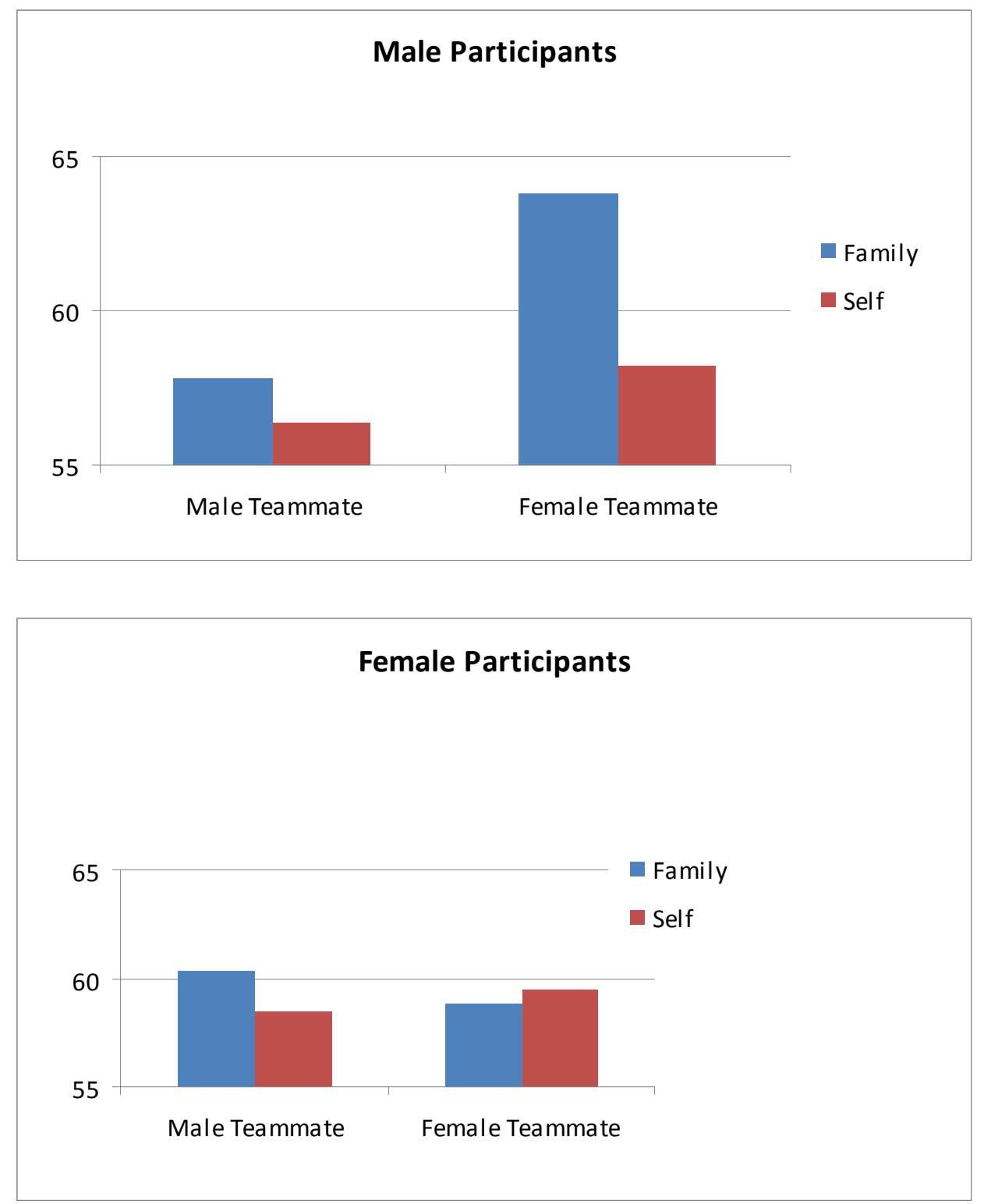

Figure 3 Interaction between participant gender, teammate gender, and type of conflict (family-related versus self-related). 
APPENDIX V: IRB HUMAN SUBJECTS PERMISSION LETTER 


\section{(c) Florida}

March 8, 2007

Kara Hickson

c/o Dr. Barbara Fritzsche

University of Central Florida

Department of Psychology

PH $311 \mathrm{~F}$

Orlando, FL 32816-1390

Dear Ms. Hickson:

With reference to your protocol \#07-4169 entitled, "Those Who Help their Families: Attributions about, Evaluation of and Social Support for People With Work-Family Conflict" I am enclosing for your records the approved, expedited document of the UCFIRB Form you had submitted to our office. This study was approved on 3/7/2007. The expiration date for this study will be $3 / 6 / 2008$. Should there be a need to extend this study, a Continuing Review form must be submitted to the IRB Office for review by the Chairman or full IRB at least one month prior to the expiration date. This is the responsibility of the investigator.

Please be advised that this approval is given for one year. Should there be any addendums or administrative changes to the already approved protocol, they must also be submitted to the Board through use of the Addendum/Modification Request form.

Changes should not be initiated until written IRB approval is received. Adverse events should be reported to the IRB as they occur.

Should you have any questions, please do not hesitate to call me at 407-823-2901.

Please accept our best wishes for the success of your endeavors.

Cordially,

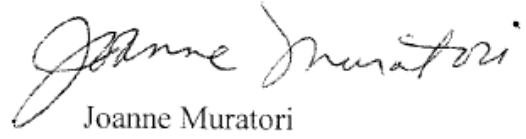

(FWA00000351 Exp. 5/13/07, IRB00001138)

Copies: IRB File

Barbara Fritzsche, Ph.D. 


\section{LIST OF REFERENCES}


Anderson, L. M., \& Pearson, C. M. (1999). Tit for tat? The spiraling effect of incivility in the workplace. Academy of Management Review, 24, 452-471.

Bailyn, L. (1993). Breaking the mold: Women, men, and time in the new corporate world. New York: Free Press.

Bakan, D. (1966). The duality of human existence: An essay on psychology and religion. Chicago: Rand-McNally.

Barr, T. F., Dixon, A. L., \& Gassenheimer, J. B. (2005). Exploring the "lone wolf" phenomenon in student teams. Journal of Marketing Education, 27, 81-90.

Batson, C. D. (1987). Prosocial motivation: Is it ever truly altruistic? In L. Berkowitz (Ed.), Advances in experimental social psychology (Vol. 20, pp. 65-122). San Diego, CA: Academic Press.

Bem, S. L. (1974). The measurement of psychological androgyny. Journal of Consulting and Clinical Psychology, 42, 155-162.

Berkowitz, L., \& Donnerstein, E. (1982). External validity is more than skin deep. American Psychologist, 37, 245-257.

Beutell, N. J., \& Wittig-Berman, U. (1999). Predictors of work-family conflict and satisfaction with family, job, career, and life. Psychological Reports, 85, 893-903.

Boles, J. S., \& Babin, B. J. (1996). On the front lines: Stress, conflict, and the customer service provider. Journal of Business Research, 37, 41-50.

Boles, J. S., Johnston, M. W., \& Hair, J. F. Jr. (1997). Role stress, work-family conflict and emotional exhaustion: Inter-relationships and effects on some work-related consequences. Journal of Personal Selling \& Sales Management, 17, 17-28. 
Bond, J. T., Thompson, C., Galinsky, E., \& Prottas, D. (2002). Highlights of the national study of the changing workforce (No. 3). New York: Families and Work Institute.

Booth, J., \& Mann, S. (2005). The experience of workplace anger. Leadership and Organization Development Journal, 26, 250-262.

Broverman, I. K., Vogel, S. R., Broverman, D. M., Clarkson, F. E., \& Rosenkrantz, P. S. (1972). Sex-role stereotypes: A current appraisal. Journal of Social Issues, 28, 5978.

Burke, R. J. (1994). Stressful events, work-family conflict, coping, psychological burnout, and well-being among police officers. Psychological Reports, 75, 787800.

Burley, K. A. (1994). Gender differences and similarities in coping responses to anticipated work-family conflict. Psychological Reports, 74, 115-123.

Carli, L. L. (1995). Nonverbal behavior, gender, and influence. Journal of Personality and Social Psychology, 68, 1030-1041.

Carlson, D. S., \& Kacmar, K. M. (2000). Work-family conflict in the organization: Do life role values make a difference? Journal of Management, 26, 1031-1054.

Carlson, D. S., Kacmar, K. M., \& Williams, L. J. (2000). Construction and initial validation of a multidimensional measure of work-family conflict. Journal of Vocational Behavior, 56, 249-276.

Carlson, D. S., \& Perrewé, P. L. (1999). The role of social support in the stressor-strain relationship: An examination of work-family conflict. Journal of Management, $25,513-540$. 
Cialdini, R. B., \& Trost, M. R. (1998). Social influence: Social norms, conformity, and compliance. In D. T. Gilbert, S. T. Fiske, \& G. Lindzey (Eds.), The handbook of social psychology (4 ${ }^{\text {th }}$ ed., Vol. 2, pp. 151-192). Boston: McGraw-Hill.

Cortina, L. M. (2008). Unseen injustice: Incivility as modern discrimination in organizations. Academy of Management Review, 33, 55-75.

Costa, P. T., Jr., Terracciano, A., McCrae, R. R. (2001). Gender differences in personality traits across cultures: Robust and surprising findings. Journal of Personality and Social Psychology, 81, 322-331.

Costa, P. T., Jr., \& McCrae, R. R. (1992). NEO PI-R professional manual. Odessa, FL: Psychological Assessment Resources, Inc.

Costrich, N., Feinstein, J., Kiddler, L., Marecek, J., \& Pascale, L. (1975). When stereotypes hurt: Three studies of penalties for sex-role reversals. Journal of Experimental Social Psychology, 11, 520-530.

Cowan, R. S. (1983). More work for mother: The ironies of household technology from the open hearth to the microwave. New York: Basic Books.

Crosby, F. J., Williams, J. C., \& Biernat, M. (2004). The maternal wall. Journal of Social Issues, 60, 675-682.

Cuddy, A. J. C., Fiske, S. T., \& Glick, P. (2004). When professionals become mothers, warmth doesn't cut the ice. Journal of Social Issues, 60, 701-718.

Cuddy, A. J. C., Norton, M. I., \& Fiske, S. T. (2005). This old stereotype: The pervasiveness and persistence of the elderly stereotype. Journal of Social Issues, $61,267-285$. 
Dipboye, R. L., \& Flanagan, M. F. (1979). Research settings in industrial and organizational psychology: Are findings in the field more generalizable than in the laboratory? American Psychologist, 34, 141-150.

Dovidio, J. F., Piliavin, J. A., Gaertner, S. L., Schroeder, D. A., \& Clark, R. D. III. (1991). The arousal: cost-reward model and the process of intervention: A review of the evidence. In M. S. Clark (Ed.), Prosocial behavior (pp. 86-118). Newbury Park, CA: SAGE Publications, Inc.

Eagly, A. H. (2000). Gender roles. In A. E. Kazden (Ed.), Encyclopedia of psychology (Vol. 3, pp. 448-453). Washington, DC: Oxford University Press.

Eagly, A. H., Makhijani, M. G., \& Klonsky, B. G. (1992). Gender and the evaluation of leaders: A meta-analysis. Psychological Bulletin, 111, 3-22.

Eisenberg, N. (1986). Altruistic emotion, cognition, and behavior. Hillside, NJ: Lawrence Erlbaum.

Eisenberg, N., \& Fabes, R. A. (1991). Prosocial behavior and empathy: A multimethod developmental perspective. In M. S. Clark (Ed.), Prosocial Behavior (pp. 34-61). Newbury Park, CA: SAGE Publications, Inc.

England, G. W., \& Misumi, J. (1986). Work centrality in Japan and the United States. Journal of Cross-Cultural Psychology, 17, 399-416.

Fiske, S. T., Cuddy, A. J. C., Glick, P., \& Xu, J. (2002). A model of (often mixed) stereotype content: Competence and warmth respectively follow from perceived status and competition. Journal of Personality and Social Psychology, 82, 878902. 
Fiske, S. T., Xu, J., Cuddy, A. J. C., \& Glick, P. (1999). (Dis)respecting versus (dis)liking: Status and interdependence predict ambivalent stereotypes of competence and warmth. Journal of Social Issues, 55, 473-489.

Frone, M. R., Russell, M., \& Cooper, M. L. (1997). Relation of work-family conflict to health outcomes: A four-year longitudinal study of employed parents. Journal of Occupational and Organizational Psychology, 70, 325-335.

Fuegen, K., Biernat, M., Haines, E., \& Deaux, K. (2004). Mothers and fathers in the workplace: How gender and parental status influence judgments of job-related competence. Journal of Social Issues, 60, 737-754.

Galinsky, E., Bond, T., \& Friedman, D. E. (1993). National study of the changing workforce. New York: Families and Work Institute.

Gilbert, L. A., \& Rader, J (2001). Current perspectives on women's adult roles: Work, family, and life. In R. K. Unger (Ed.), Handbook on the psychology of women and gender (pp. 156-169). Hoboken, NJ: John Wiley \& Sons, Inc.

Goff, S. J., Mount, M. K., \& Jamison, R. L. (1990). Employer supported child care, work/family conflict, and absenteeism: A field study. Personnel Psychology, 43, 793-809.

Good, L. K., Page, T. J. Jr., \& Young, C. E. (1996). Assessing hierarchical differences in job-related attitudes and turnover among retail managers. Journal of the Academy of Marketing Science, 24, 148-156.

Good, L. K., Sisler, G. F., \& Gentry, J. W. (1988). Antecedents of turnover intentions among retail management personnel. Journal of Retailing, 64, 295-314. 
Gorman, K. A., \& Fritzsche, B. A. (2002). The good-mother stereotype: Stay at home (or wish that you did!). Journal of Applied Social Psyschology, 32, 2190-2201.

Greenhaus, J. H., \& Beutell, N. J. (1985). Sources of conflict between work and family roles. Academy of Management Review, 10, 76-88.

Hebl, M.R., King, E. B., Glick, P., Singletary, S. L., \& Kazama, S. (2007). Hostile and benevolent reactions toward pregnant women: Complementary interpersonal punishments and rewards that maintain traditional roles. Journal of Applied Psychology, 92, 1499-1511.

Higgins, C. A., Duxbury, L. E., \& Irving, R. H. (1992). Work-family conflict in the dualcareer family. Organizational Behavior and Human Decision Processes, 51, 5175.

House, G. S. (1981). Work stress and social support. Reading, MA: Addison-Wesley. International Personality Item Pool (n.d.). Agreeableness longer scale. Retrieved March 18, 2008, from http//ipip.ori.org/newBigFive5broadKey.htm

Jiminez, M. (2008, April). Coworker informal work accommodations to family: Scale development and validation. Poster session presented at the 2008 UCF Graduate Research Forum: The Fifth Annual Showcase of Diverse Student Research, Orlando, FL.

Jones, E. E., \& Nisbett, R. E. (1987). The actor and the observer: Divergent perceptions of the causes of behavior. In E. E. Jones \& D. E. Kanouse (Eds.), Attribution: Perceiving the causes of behavior (pp. 79-94). Hillsdale, NJ: Lawrence Erlbaum Associates, Inc. 
Kahn, R. L., Wolfe, D. M., Quinn, R., Snoek, J. D., \& Rosenthal, R. A. (1964). Organizational stress. New York: Wiley.

Kanter, L. H. (1977). Can women think? Transactional Analysis Journal, 7, 251.

Kelly, C., \& Kelly, L. ESL/EFL basic vocabulary word lists. (n.d.). In Interesting things for ESL students. Retrieved from http://manythings.org/vocabulary/lists/a/

Kossek, E. E., \& Ozeki, C. (1998). Work-family conflict, policies, and the job-life satisfaction relationship: A review and directions for organizational behavior - human resources research. Journal of Applied Psychology, 83, 139-149.

Lippa, R. (1991). Some psychometric characteristics of gender diagnosticity measures: Reliability, validity, consistency across domains, and relationship to the Big Five. Journal of Personality and Social Psychology, 61, 1000-1011.

Livingston, M. M., Burley, K., \& Springer, T. P. (1996). The importance of being feminine: Gender, sex role, occupational and marital role commitment, and their relationship to anticipated work-family conflict. Journal of Social Behavior and Personality, 11, 179-192.

Lundberg, C. D., \& Peterson, M. F. (1994). The meaning of working in U.S. and Japanese local governments at three hierarchical levels. Human Relations, 47, 1459-1487.

National Alliance for Caregiving and American Association of Retired Persons (2004). Family caregiving in the U. S.: Findings from a national survey. Retrieved from http://www.caregiving.org on April 10, 2008.

Nielson, T. R., Carlson, D. S., \& Lankau, M. J. (2001). The supportive mentor as a means of reducing work-family conflict. Journal of Vocational Behavior, 59, 364-381. 
Pfaff, E., \& Huddleston, P. (2003). Does it matter if I hate teamwork? What impacts student attitudes toward teamwork. Journal of Marketing Education, 25, 37-45.

Penner, L. A., Fritzsche, B. A., Craiger, J. P., \& Freifeld, T. S. (1995). Measuring the prosocial personality. In J. N. Butcher \& C. D. Spielberger (Eds.), Advances in personality assessment (Vol. 10, pp. 147-163). Hillsdale, NJ: Lawrence Erlbaum Associates, Inc.

Rexroat, C., \& Shehan, C. (1987). The family life cycle and spouses' time in housework. Journal of Marriage \& the Family, 49, 737-750.

Rudolph, U., Roesch, S. C., Greitmeyer, T., \& Weiner, B. (2004). A meta-analytic review of help giving and aggression from an attributional perspective: Contributions to a general theory of motivation. Cognition and Emotion, 18, 815-848.

Sayer, L. C. (2001). Time use, gender, and equality: Differences in men's and women's maket, non-market, and leisure time. Unpublished doctoral dissertation, University of Maryland, College Park.

Schwartz, F. (1989). Management women and the new facts of life. Harvard Business Review, 67, 65-76.

Shelton, B. A. (1992). Women, men, and time: Gender differences in paid work, housework, and leisure. New York: Greenwood Press.

Tabachnick, B. G., \& Fidell, L. S. (2001). Using multivariate statistics (4th ed.). Needham Heights, MA: Allyn \& Bacon.

Thompson, C. A., \& Blau, G. (1993). Moving beyond traditional predictors of job involvement: Exploring the impact of work-family conflict and overload. Journal of Social Behavior and Personality, 8, 635-646. 
U.S. Census Bureau. (2000). Census 2000 Summary File 3. Washington, DC: Author.

U.S. Census Bureau. (2005). Statistical Abstract of the United States, 2004-2005. Washington, DC: Author.

U.S. Department of Labor, Bureau of Labor Statistics. (2000). Are managers and professionals really working more? Washington, DC: Author.

Weiner, B. (1995). Judgments of responsibility: A foundation for a theory of social conduct. New York: The Guilford Press

Williams, K. J., \& Alliger, G. M. (1994). Role stressors, mood spillover, and perceptions of work-family conflict in employed parents. Academy of Management Journal, $37,837-868$.

Winfrey, O. (2003, April). O Magazine. 